\title{
Subjective Well-Being in Swedish Women
}

Daiva Daukantaite

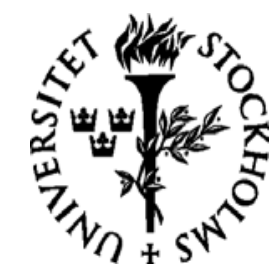

DEPARTMENT OF PSYCHOLOGY

STOCKHOLM UNIVERSITY

2006 
Cover photograph: 'Daydreamer' by Lars Raun Reprinted with kind permission from Lars Raun

(C) Daiva Daukantaite ISBN 91-7155-337-1

US-AB, Stockholm 2006 
To Donatas and Britt-Inger, For love and endless support 

Doctoral dissertation 2006

Department of Psychology

Stockholm University

Sweden

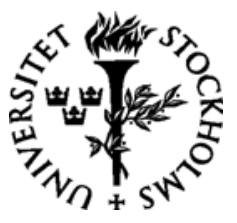

Abstract

The present thesis concerns middle-aged women's subjective well-being (SWB). The interest is focused on the importance of childhood factors, social circumstances, and personality for middle-aged women's general SWB. Data were taken from the longitudinal research program Individual Development and Adaptation (IDA, Magnusson \& Bergman, 2000) and concerned a sample of about 300 women. The main analyses were made on data collected at age 43, but data collected at age 13 and age 49 were also used to elucidate the purposes of this thesis. The results can be summarized as follows: 1) In a Swedish sample of middle-aged women, social circumstances had only a moderate effect on general SWB variables. The strongest relationship was found between marital status and global life satisfaction. When personality factors were controlled for, they wiped out nearly all relationships between the social circumstances variables and SWB, except for those between global life satisfaction and marital status or unemployment; 2) The level of general SWB was found to be considerably higher for Swedish employed women as compared to their counterparts in Lithuania and different socio-demographic variables predicted SWB in those two countries. For the Swedish sample, family-oriented variables were the strongest predictors of SWB, while for the Lithuanian sample income and educational level were more important; 3) Results from applying longitudinal structural equation modeling suggested that optimism in adolescence influenced optimism in middle age, which in its turn had both a direct influence on global life satisfaction and an indirect influence via the negative affect dimension. In relation to a number of different adjustment factors measured in adolescence it was found that optimism was the only factor that was constantly related to SWB 30 years later; 4) Typical patterns of general SWB were identified. Cluster analyses at age 43 and age 49 separately resulted in similar well-functioning six cluster solutions at both ages, indicating structural stability across six years. In addition to the typical high/low/average SWB clusters that could be to some degree expected from variable-oriented results, a cluster with intense affect and one with very low GLS emerged. All clusters except the latter one showed individual stability across six years.

Key words: women, subjective well-being, longitudinal, cluster analysis, social circumstances, personality. 



\section{Acknowledgments}

The research presented in this thesis has been made possible by access to data from the longitudinal research program - Individual Development and Adaptation (IDA) once led by David Magnusson and now by Lars R. Bergman. Part of the presented research has been supported by a grant to Lars R. Bergman from the Swedish Council for Working Life and Social Research.

This dissertation marks the end of a long and eventful journey, during which I have learned so much and met so many wonderful people who, in different ways, contributed not only to my work but also to my personal growth.

First of all, I would like to thank Rita Zukauskiene. I'm almost sure that this dissertation would not be in your hands if Rita hadn't been my supervisor for my master thesis many years ago. She was not only an outstanding supervisor and an interesting lecturer, but also a person without whose encouragement I would not have considered continuing my studies in psychology. And not only that - thank you, Rita, for "building" bridges to Stockholm.

I would like to express my sincerest gratitude to my supervisor, Lars R. Bergman, whose expertise, understanding, calmness, and patience added considerably to my graduate experience. I am very thankful to you, Lars, for always having time for me, your quick and insightful comments on my articles, and allowing me to be a "distance" student for a while. I am happy that our communication and understanding has grown during these years.

My sincere gratitude goes to Joar Vittersø and Magnus Sverke for their constructive comments on a previous version of this dissertation. Thank you also, Joar, for the pleasant conversations and discussions during different conferences. Magnus, thank you for all your help with Lisrel and other matters - you still blow me away with your amazing sharpness, knowledge, and communication skills.

I am very grateful to Luki Hagen. Without her help, my first years in the department would have been much tougher. I am also sincerely grateful to Barbro Svensson for all her help with administrative matters. My thanks for technical help and support go to the wonderful team of IT specialists: Bernard Devine, Karl Arne Tingström, and Peter Almlöf. I would like also to thank Lisa Duffy for revising my English. 
I am thankful to my colleagues who in various ways have been support in my work: Mia Körlof, Robert Brage, Kari Trost, Peter Zettergren, Chris Magnusson, Bassam El-Khouri, and Siv Lindroth. Many thanks go to Viera Gantner and Ola Andersson for their help with administrative and technical matters. I would like to thank Qinghai Huang, Göran Söderlund, and other people in the department for your friendship and the moments of laughter. Special thanks go to Karen Benzies (University of Calgary) for all the joy and warmth she brought into our group during the time she was here.

My sincere thanks go to Reidar Österman for ... It is too much to list everything. Thanks for being there!

Outside the university, my friend Sandra has always been someone (since grade school) who is just a perfect person to talk about everything. It is an invaluable gift to have a friend such as you.

My special, sincerest thanks go to the Lithuanian friends I made when I moved to Stockholm: Valentinas, Aurelija, and Darius. I am deeply indebted to you all for helping me solve the problems that come along with living in two countries. Thanks also for a great time in Stockholm!

My studies in Stockholm also led me to meet Vilmante. Thank you, Vilma, for our many long chats concerning both science and life outside it.

Britt-Inger, my Swedish Mom, I am so grateful to you for all your support and encouragement during these long years. You've always been on my side.

To my family and Donatas' family for all your help and support.

And finally, to my dearest people, Donatas and Linas: with large and little hearts you give love and transform my love to the fuel that makes my life's engine function.

With love,

Daiva Daukantaite

September in sunny Stockholm, 2006 


\section{List of studies}

The present thesis is based on the following four studies, which will hereafter be refereed to by their Roman numerals.

Study I Bergman, L. R., \& Daukantaitè, D. (2006). The importance of social circumstances for Swedish women's subjective well-being. International Journal of Social Welfare, 15, 27-36.

Reproduced with permission from the International Journal of Social Welfare, (C) 2006 Blackwell Publishing Ltd.

Study II Daukantaite, D., \& Zukauskiene, R. (2006). Swedish and Lithuanian employed women's subjective well-being. International Journal of Social Welfare, 15, S23-S30.

Reproduced with permission from the International Journal of Social Welfare, (C) 2006 Blackwell Publishing Ltd.

Study III Daukantaite, D., \& Bergman, L. R. (2005). Childhood roots of women's subjective well-being: The role of optimism. European Psychologist, 10, 287-297.

Reproduced with permission from the European Psychologist, (C) 2005 Hogrefe \& Huber Publishers.

Study IV Bergman, L. R., \& Daukantaite, D. (submitted). Stability of typical patterns of subjective well-being in middle-aged Swedish women. 



\section{Contents}

1. Introduction...............................................................................................................................1

1.1. The traditions in the study of well-being in psychology......................................... 1

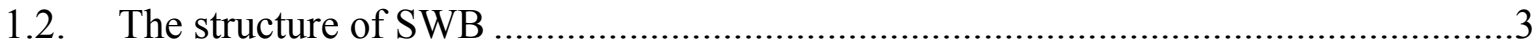

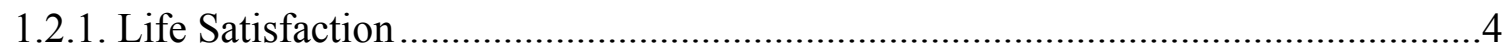

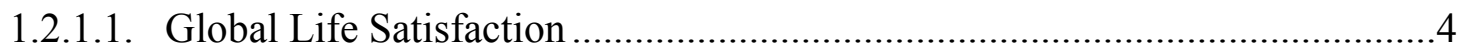

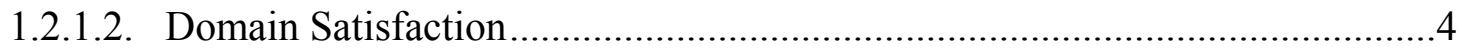

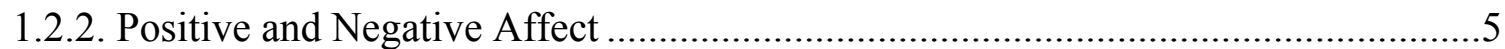

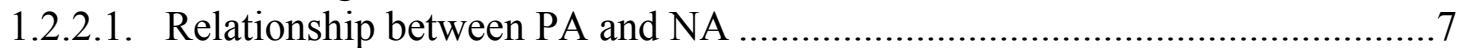

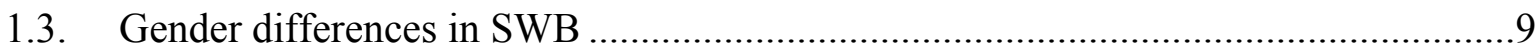

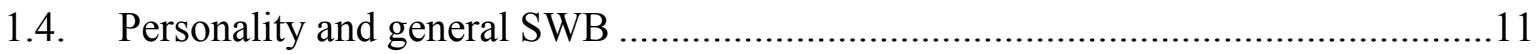

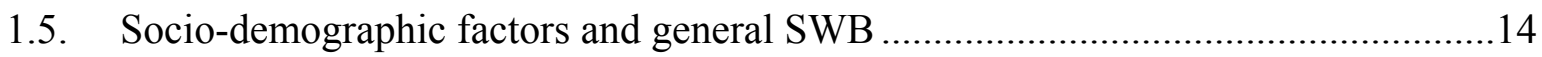

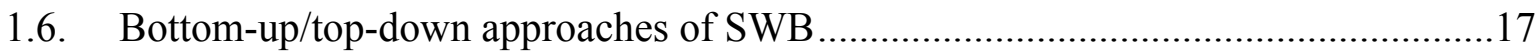

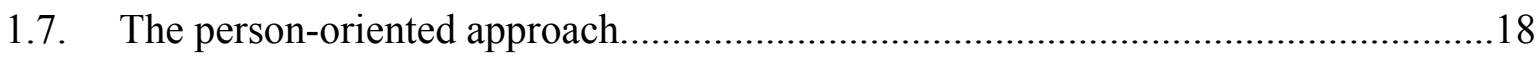

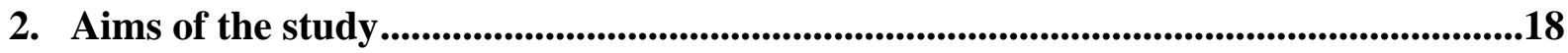

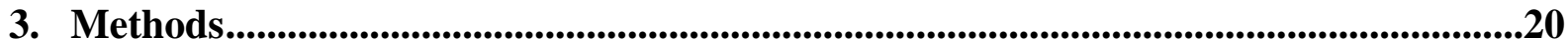

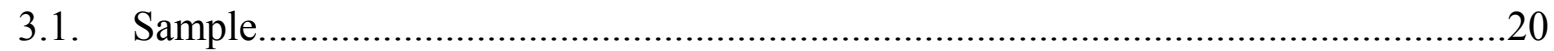

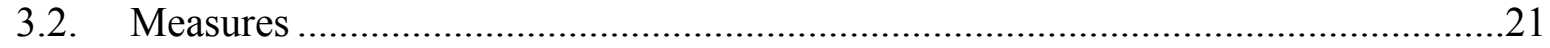

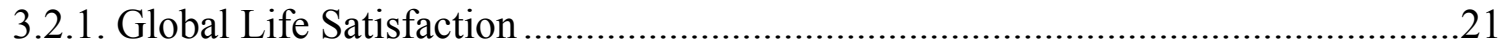

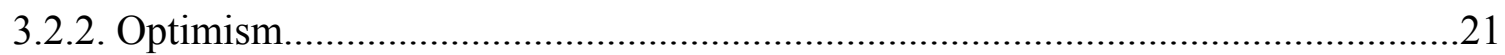

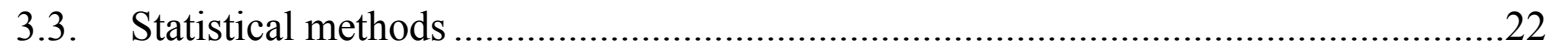

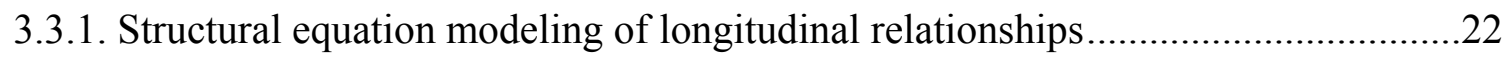

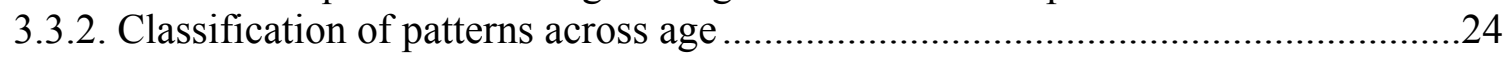

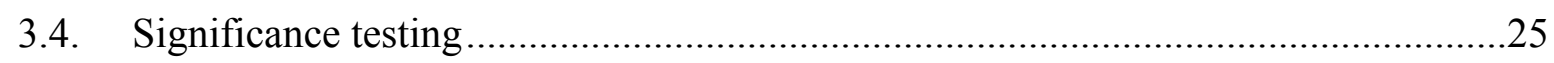

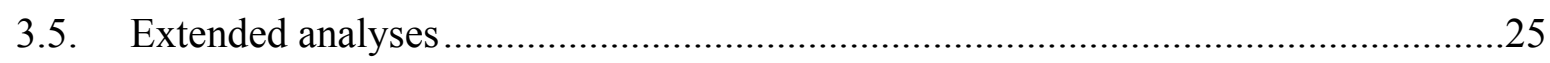

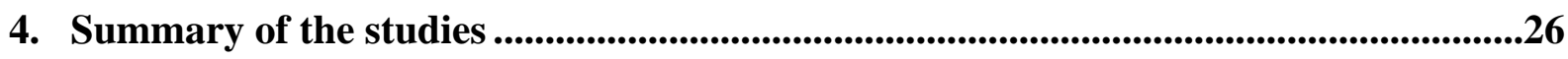

4.1. Study I. The importance of social circumstances for Swedish women's subjective

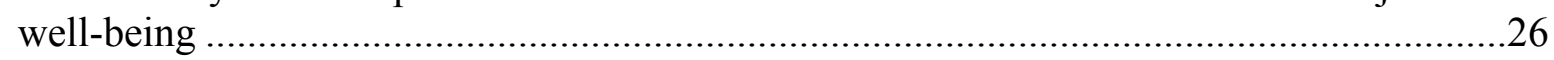

4.2. Study II. Swedish and Lithuanian employed women's subjective well-being ..........27

4.3. Study III. Childhood roots of women's subjective well-being: The role of optimism28

4.4. Study IV. Stability of typical patterns of subjective well-being in middle-aged

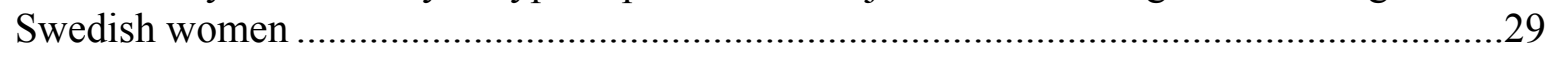

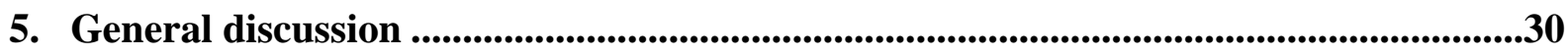

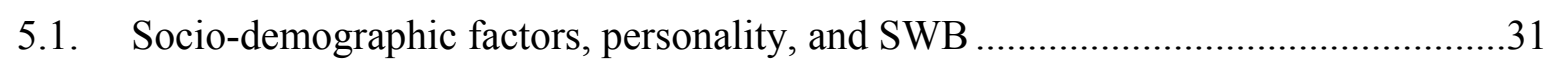

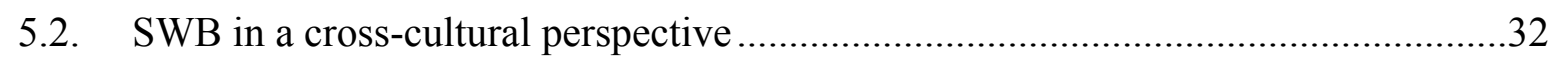

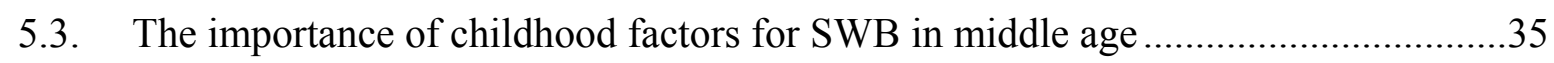




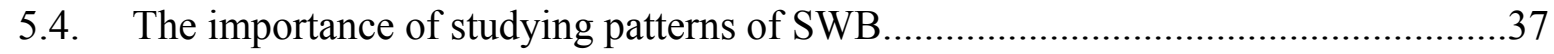

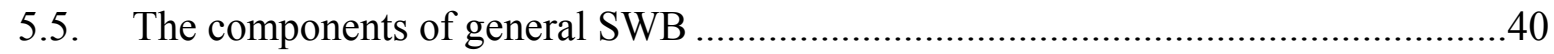

5.6. The direction of relationships - bottom-up/top-down approaches ..........................42

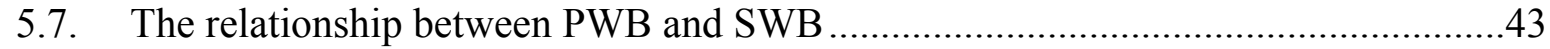

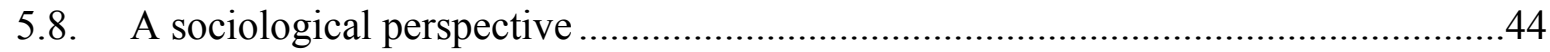

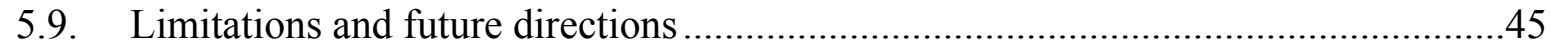

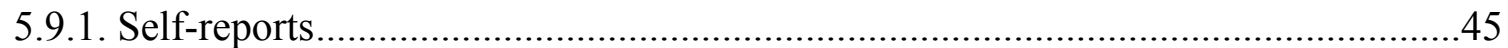

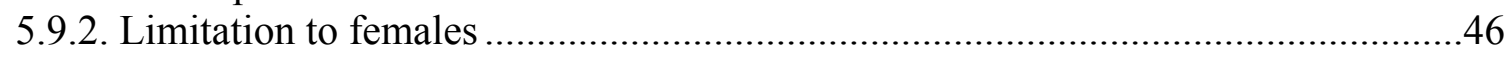

5.9.3. The need for more cross-cultural research.....................................................46

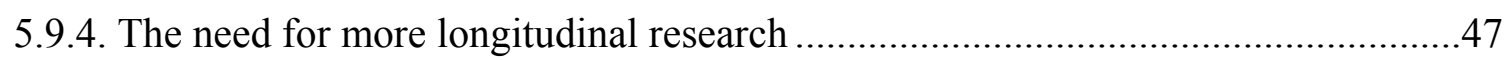

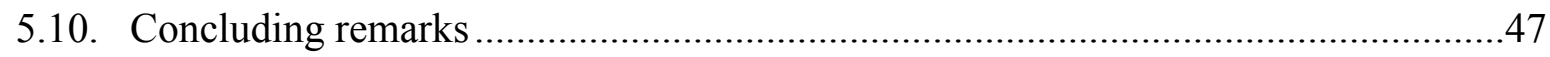

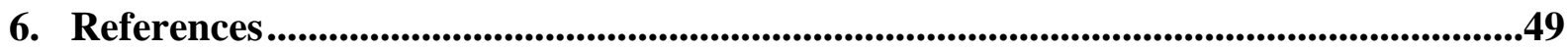




\section{Introduction}

The magnitude of life satisfaction and happiness is one important aspect of the quality of life in today's society (Diener \& Lucas, 2000). Women's life conditions are now dramatically different from what they were just a few decades ago. Looking at the positive side of a changed society, we see that the material standard of living has risen, people live longer and are healthier, more possibilities for self-actualization have emerged, and so on. Looking at the negative side, we see that families are less stable, and that time-pressure and stress may have increased for many women. The distribution of welfare and factors that are of importance for it have been the subject of a considerable body of research, which has often been carried out within a sociological framework. As such, the focus has often been on the resources that people have at their disposal - as is the case within what is known as the Scandinavian approach to welfare research (Erikson \& Uusitalo, 1987).

The present thesis is concerned with one sub-area of women's welfare, namely their general subjective well-being (SWB) and factors related to it. Nowadays, this is largely a research field within psychology (Diener, Suh, Lucas, \& Smith, 1999), and in this thesis, SWB is studied within this framework. Numerous studies have been published since 1967, when one of the pioneers of SWB, Wilson, published his broad review of happiness. However, research on SWB remains rather fragmented and is based primarily on youthful (for example, student), mixed (not gender specific) samples. This thesis is devoted to middleaged females' SWB. Studies of women in midlife often tend to focus on problems related to the menopause, physical changes, children leaving home, and so on. However, regardless of changes in biological, psychological, and social functioning during that time period, many middle-aged women are settled in a long-term loving relationship, have committed themselves to a career, established a family and a permanent home, and so on, and are therefore likely to have the prerequisites to being satisfied with their lives. The major interest in this thesis relates to the importance of childhood factors, socio-demographic conditions, and personality for women's general SWB in middle age.

\subsection{The traditions in the study of well-being in psychology}

Although the question of How to attain happiness has been an important one for philosophers, writers, and social scientists since ancient times, the approach to 
studying happiness and a person's well-being has altered through the years. Well-being has been given many different meanings and has been defined in many different ways - for instance, as virtue or holiness, a pleasant emotional experience, a subjective evaluation of life in positive terms, the actualization of human potential, optimal psychological functioning, and so on (Diener, 1984; Ryff, 1995; Ryan \& Deci, 2001). It is probably fair to say that the disagreement on the definition of the concept of well-being and the innate "fuzziness" of the concept, together with a concentrated attention on research on human unhappiness, have hindered the progress of conceptualization and measurement of human positive functioning. However, in the last few decades, this situation has changed. Nowadays, it is usually two perspectives of well-being: psychological and subjective (or eudaimonic and hedonic), that are studied. Ryan and Deci (2001) noted that these perspectives have been formed from two philosophies - eudaimonism and hedonism - and that they are relatively distinct, yet overlapping. The first view, inspired by Aristotle, refers to realization of a person's "daimon" or true nature, rather than personal happiness (Waterman, 1993). Waterman suggested that eudaimonia occurs when a person's life activities are congruent with deeply-held values that are fully engaged. In the eudaimonic view, Ryff and her colleagues explored the question of well-being (see Ryff \& Keys, 1995; Ryff \& Singer, 1998, 2000) and developed a lifespan theory of human flourishing. They described well-being as "the striving for perfection that represents the realization of one's true potential" (Ryff, 1995, p. 100) and presented a multi-dimensional approach to the measurement of psychological well-being (PWB) that consists of six distinct aspects of human actualization: autonomy, personal growth, self-acceptance, life purpose, mastery, and positive relatedness.

The other view, hedonism, also has a long history and has been expressed in many forms - from a relatively narrow focus on bodily pleasures to a broad focus on self-interests and appetites (Ryan \& Deci, 2001). The hedonic view adopted by psychologists focuses on a much broader conception of hedonism, including a whole spectrum of preferences and pleasures of the mind, as well as the body (Kubovy, 1999). Kahneman, Diener, and Schwarz (1999) pointed out that "hedonic" is often used to refer solely to pleasure, but that hedonic psychology covers a wide range of aspects - both affective (pleasure and pain, joy and sorrow, and so on), biological, and societal - that occasion suffering and enjoyment, and also include different levels of psychological analysis. Within the hedonic tradition, subjective well-being (SWB) is a key phenomenon central to the present thesis and as such it is defined and discussed in subsequent sections. 


\subsection{The structure of SWB}

As mentioned above, SWB is a key phenomenon within the hedonic tradition and refers to a cognitive and affective evaluation of a person's life (Diener, 1984). It is often regarded as including three separable components: life satisfaction (LS, global judgments of one's life), positive affect (PA, pleasant emotions and moods), and negative affect (NA, unpleasant emotions and moods). Life satisfaction, the cognitive component of SWB, can be divided into global life satisfaction and satisfaction with specific domains. When referring to general SWB in the thesis, I mean that it comprises global life satisfaction, positive affect and negative affect. Although the tripartite structure of SWB is widespread and accepted by a great number of researchers, the phenomenon has a weak theoretical base. The scientific construct of SWB emerged from surveys that were conducted for other purposes (e.g., to determine how demographic factors influence one's well-being, Campbell, Converse, \& Rodgers, 1976). It has been criticized for lacking a clear conceptual framework and for giving little attention to the fundamental meaning of SWB (Ryff \& Keyes, 1995). Although some attempts to unify the field have been made (for example, Diener \& Lucas, 2000), a unified conception on SWB is still lacking. The main focus has been on what factors are essential for one's SWB. Personality, cognitive, and social psychologists have studied how personality factors, adaptation, and varying standards influence people's evaluation and feelings of their well-being (e.g., Brickman \& Campbell, 1971; Diener, 1984; Parducci, 1995). The results and theories concerning the factors important for SWB are reviewed and discussed in the subsequent sections of the Introduction.

Diener (1984) reviewed a number of SWB scales and formulations. One of the first formulations that laid the foundation for the current formulation of SWB was suggested by Bradburn (1969). He stressed a preponderance of PA over NA. This formulation may mean either that the person is experiencing mostly pleasant emotions during the reference period or that the person is predisposed to such emotions, whether or not he or she is currently experiencing them. Andrews and Withey (1976) found that LS formed a separate factor from the two major types of affect. Thus, in addition to the affective dimensions introduced by Bradburn, they added a cognitive aspect. Lucas, Diener, and Suh (1996) performed multitrait-multimethod analyses and demonstrated that PA, NA, and LS were separate but related constructs that can be regarded as parts of a higher order construct (Argyle, Martin, \& Crossland, 1989; Lucas et al., 1996; Diener, 2000). The cognitive and affective components of SWB have been found to exhibit stability across time and this has been explained by the fact that biologically-based personality predispositions are likely to be crucial for general 
SWB (Costa \& McCrae, 1980). The issue is reviewed and discussed in subsequent sections.

\subsubsection{Life Satisfaction}

As mentioned above, life satisfaction can be divided into global life satisfaction and satisfaction with specific domains that are discussed below.

\subsubsection{Global Life Satisfaction}

Global life satisfaction (GLS) refers to a person's evaluation of his/her life as a whole (Diener, 1984). Unlike PWB, which specifies in advance the aspects of human potential that a person is striving to realize; in SWB research, a person determines the standards and criteria herself/himself when evaluating her/his GLS. One of the major challenges of SWB is understanding how people choose the standards to produce these evaluations. Many different factors have been identified as being important for determining the level of a person's GLS and a number of those factors are discussed in subsequent sections.

Different questionnaires with a varying number of items and covering a reference period ranging from a few weeks to the person's entire life have been used to measure the phenomenon (for a review, see Diener, 1984). A one-item scale to measure GLS was developed by Andrews and Withey (1976). The question is as follows: "How do you feel about your life as a whole?" with answers given on a seven-point scale ranging from "delighted" to "terrible". Although it is often argued that one-item scales have low reliability, the scale showed surprisingly high reliability with a correlation of .77 for two administrations of the item (Andrews \& Robinson, 1991). The scale that probably most often is used to measure GLS is The Satisfaction with Life Scale (SWLS) developed by Diener, Emmons, Larsen, and Griffin (1985). The scale was found to be valid and reliable, and correlates substantially with reports by family and friends of the target person's life satisfaction (Pavot \& Diener, 1993).

\subsubsection{Domain Satisfaction}

Satisfaction with specific domains refers to a person's experience of satisfaction with specific life domains - such as their job, partner, friends, and so on. In this thesis, domain satisfaction per se is not at focus; it is studied for the purpose of validating the trustworthiness of the general SWB typical profiles (Study IV) and as additional measures of SWB in relation to socio-demographic variables 
(Study II). Nevertheless, it is of interest to give a brief overview of SWB with regard to selected specific domains and its relationship to general SWB.

Marital satisfaction (i.e., satisfaction with the relationship with one's partner) is a domain that has been found to be substantially related to general SWB (e.g., Dush \& Amato, 2005). A number of studies have showed that happily married people have better mental health and report lower levels of distress and higher levels of general SWB than those who are unhappily married (Williams, 2003; for a review, see Glenn, 1990).

Work tends to be an integral and defining aspect in adult life. As such, in our analyses, we included job satisfaction as another domain that has an important connection with happiness in adulthood. Job satisfaction is often considered in terms of intrinsic (e.g., opportunities for advancement and growth) and extrinsic factors (e.g., pay). Tait, Padgett, and Baldwin (1989) examined 34 studies and reported that the average correlation between life satisfaction and job satisfaction was .44. In a number of studies, job satisfaction has been related to educational level (for a review, see Ganzach, 2003) and the results are somewhat mixed, in that both a positive and a negative relationship to job satisfaction have been reported.

"Good health" obtained the highest rating when respondents were asked to judge the importance of different domains of their lives (Campbell et al., 1976). However, the strong relationship between general SWB and health holds only for self-reported health measures (e.g., Okun, Stock, Haring, \& Witter, 1984), while when objective health ratings by physicians are examined, the relationship becomes much weaker (e.g., Watten, Vassend, Myhrer, \& Syversen, 1997). It has been suggested that self-rated health measures reflect not only the actual physical condition, but also the emotional state (Hooker \& Siegler, 1992) and are related to personality factors (e.g., Larsen, 1992, Brief, Butcher, George, \& Link, 1993).

\subsubsection{Positive and Negative Affect}

The affective component of SWB comprises PA and NA. Considering the expected intensity and duration of emotional experiences, emotions may be conceptualized as discrete vs. dimensional, states vs. traits, event-related vs. diffuse. Most discussion has been devoted to the first issue. That is, whether emotions operate as separate and distinct classes of experience or as two/three general dimensions. 
The proponents of the discrete view of emotions suggest that there are a limited number of emotions that represent a class or "family" of emotions (Lazarus, 1991; Ekman, 1992). The emotions that belong to a class are specifications of the corresponding basic emotion regarding, for example, its intensity (for example, rage is a high-intensity sub-class of anger), and so on. Lists of the basic emotions vary from one author to another, but show considerable overlap. The basic emotions included in most lists are as follows: joy or happiness, sadness or distress, fear, anger, and disgust or aversion (Frijda, 1999). The proponents of the discrete view argue that the dimensional view of emotion blurs meaningful distinctions between the adjacent emotions (Ekman, 1992).

The dimensional view of emotions suggests that emotions vary across a few major common dimensions. Historically, efforts to identify the dimensional structure of emotions go back to Wundt (1912/1924, cited in Laukka, 2004). Through multi-dimensional scaling, semantic differential technique, factor analyses, and other techniques, two to three dimensions have been proposed. The two dimensions found in many studies are affective valence (also called evaluation or pleasure) and activation (also called arousal or activity). The first dimension ranges from pleasant over neutral to unpleasant; the second from low to high. A third dimension has been labeled as "control" by Osgood et al. (1975) or as "dominance" by Russell and Mehrabian (1977). The dimensional view of emotion is often represented by a circumplex model (Russell, 1980; Watson \& Tellegen, 1985; for a review, see Larsen \& Diener, 1992). Contrary to the simple structure that posits that emotions fall into clusters 90 degrees apart, the circumplex model posits that emotions conform to a circular arrangement and coordinates in the circular space that represents valence and arousal. Emotions that are similar to each other (for example, unhappy, sad) are close to each other on the circumference of the circle, whereas emotions that seem to be opposites (for example, anxious and relaxed) are 180 degrees away from each other. Almost no one suggests that individual affect shows the traditional simple structure or that affect items are spaced perfectly evenly around the circle.

Watson and Tellegen's (1985) research on PA and NA led to an alternative twodimensional structure. They suggested that PA and NA are relatively pure markers of the two valenced activation dimensions - high vs. low positive affect and high vs. low negative affect - and that those dimensions are different from a pleasantness/unpleasantness dimension. Although in their early study (1985) the researchers claimed that they were able to demonstrate a circular structure that was designed to closely resemble Russell's circumplex (1980), in more recent studies they concluded that their model falls "somewhere between the classic, simple structure and a true circumplex" (Watson, Wiese, Vaidya, \& Tellegen, 1999, p. 820). 
Watson et al. (1988) defined high PA as a general state when a person feels, for example, enthusiastic, active, and low PA as when a person feels sad and lethargic. High NA was defined as a general state when a person feels, for example, afraid, guilty, and low NA was defined as being a state of calmness and serenity. Although the PA and NA dimensions were initially interpreted in terms of valence - high (e.g., enthusiastic) and low PA (e.g., sad, lethargic), and high (e.g., hostile) and low NA (e.g., calm, serene), the dimensions are predominantly defined by positively valenced and negatively valenced terms respectively, and are seen as truly uni-polar constructs (Watson et al., 1999). The latter characteristics are clearly seen in the Positive and Negative Affect Schedule (PANAS) developed by Watson et al. (1988). The ten positive affect items included in PANAS are enthusiastic, interested, determined, excited, inspired, alert, active, strong, proud, and attentive. The ten negative affect items included in PANAS are scared, afraid, upset, distressed, jittery, nervous, ashamed, guilty, irritable, and hostile. Thus, the positive factor consists of positive terms that seem to be high in activation (e.g., excited, active, alert), and the negative factor consists of negative terms that also seem to be high in activation (e.g., jittery, hostile).

\subsubsection{Relationship between PA and NA}

A number of investigators have viewed PA and NA as orthogonal dimensions (Bradburn, 1969; Diener \& Emmons, 1985; Zevon \& Tellegen, 1982), but this standpoint is still disputed. In order not to go too far into the debates on this issue, I have limited myself to reviewing the major factors that have been shown to influence the relationship between PA and NA. For a review of the issues of independence vs. bipolarity of PA and NA, see Russell and Carroll (1999) and Watson and Tellegen (1999).

Based on the empirical results and the available evidence, Russell and Carroll (1999) concluded that the relationship between PA and NA is influenced by a number of factors, including: 1) what items were selected to assess PA and NA; 2) random and systematic errors in measurement; and 3) the response format used in the affect measurement.

The affect dimensions lack a consensual definition. Researchers have not agreed upon what states should be included/excluded in the definition and hence what words/phrases should comprise an affect questionnaire (Russell \& Carroll, 1999). This lack of agreement has resulted in a number of questionnaires, which include different terms to describe PA and NA. It is, then, hardly surprising that reported correlations between PA and NA have varied depending on the instrument used for measuring affect. 
In the previous section, I listed the PA and NA items that were included in PANAS, a standard instrument for measuring PA and NA (Watson et al., 1988). The main critique of PANAS is that the scales do not cover the full range of PA or NA. That is, the terms that are generally accepted as defining PA - for instance, happy, satisfied; or NA - for instance, unhappy, sad, depressed, are missing. However, Watson et al. (1988) argued that such terms vary along the pleasantness vs. unpleasantness dimension, whereas the positive vs. negative items included in PANAS were chosen to tap the theoretical dimensions of PA and NA that were defined as opposite valenced high-arousal dimensions.

Systematic and random errors in measurement constitute the second factor that has been found to alter the observed relationship between PA and NA. Bentler (1969) showed that a systematic or non-random error, particularly an acquiescent response style (i.e., the tendency to agree or disagree with an item regardless of its content), influenced the correlation. Consistent with the finding by Bentler, a number of researchers have found that an acquiescent response style and other systematic errors tend to influence affect ratings (Hunter \& Schmidt, 1990; Russell, 1979; Tellegen, Watson, \& Clark, 1994). Green, Goldman, and Solovey (1993), instead of examining each type of error separately, used a variety of different response formats to measure the same phenomenon and applied structural equation modeling to analyze the data. They found that the observed correlations were much lower compared to correlations between the latent affect scales. For instance, the observed correlation between scales measuring happiness and sadness varied from -.25 to -.69, and the correlation between the latent scores of the scales was found to be -.84 to -.93 . Watson and Tellegen (1999) reviewed correlations separately for three types of affect descriptors: 1) pleasantness vs. unpleasantness (e.g., happy vs. sad); 2) high vs. low activation (e.g., aroused vs. quiet), and 3) positive vs. negative activation (e.g., enthusiastic vs. scared). The results showed that the mean uncorrected correlations ranged from -.53 to $-.78,-.45$ to -.54 , and -.18 to -.36 , respectively, for the pleasantness vs. unpleasantness, high vs. low activation, and positive vs. negative activation terms. When the correlations were controlled for measurement error (i.e., latent correlations), the correlations increased and ranged from -.84 to $-.93,-.73$ to -.79 , and -.43 to -.58 , respectively, for the three types of affect descriptors. Thus the latent correlations were consistently higher than the uncorrected manifest correlations, and the largest correlations were found between the terms included in the pleasantness vs. unpleasantness scales.

The third factor that it is claimed influences the relationship between PA and NA is the response format. Russell and Carroll (1999) listed eleven response formats that were grouped into five types, ranging from strictly unipolar to 
strictly bipolar. The authors argued that if a strictly unipolar response format is used for a bipolar item format, the response format assesses only part of the information and results in a reduction of the correlation between PA and NA. Warr, Barter, and Brownbridge's (1983) results also pointed to the influence of the response format on the relationship between PA and NA. They found that the relationship between PA and NA was as low as -.01 when a simple yes-no format was used, but that the correlation increased to -.54 when a proportion-oftime response format was used.

In addition to the three factors mentioned above, the time frame of the ratings is an additional factor influencing the relationship between PA and NA. Diener and Emmons (1985) found PA and NA to be almost independent when measured over a longer period of time (e.g., the past year), but the factors were inversely strongly correlated when measured for the past month. The correlation becomes even stronger when the respondents were asked to report daily and momentary affect. The authors concluded that it is very unlikely that a person can feel both PA and NA at the same time (see also Russell and Carroll, 1999; Russell, 1979). However, Cacioppo and his colleagues (e.g., Cacioppo \& Berntson, 1994; Larsen, McGraw, \& Cacioppo, 2001) proposed that it is possible for people to feel both happy and sad at the same time. They found that in specific circumstances (e.g., graduating from college or after watching an emotional film) mixed feelings of happiness and sadness could co-occur (see also Diener \& Iran-Nejad, 1986). In addition to this, Diener and Emmons (1985) suggested that PA and NA are negatively related on a frequency dimension, but that on an intensity dimension, PA and NA can covary (see also Diener, Larsen, Levine, \& Emmons, 1985).

\subsection{Gender differences in SWB}

Although this thesis is concerned with women's SWB, it can be helpful to briefly review gender differences in SWB in order to put the findings of the thesis in context.

Only a few studies have found significant gender differences in general SWB, but results are often inconsistent. For instance, in an international comparative study involving analysis of data from 41 countries, Haller and Hadler (2006) found that women scored significantly higher both on life satisfaction and overall happiness; whereas in an extensive meta-analytic review of 93 studies, Haring, Stock, and Okun (1984) reported a slight tendency for men to report higher levels of happiness. However, clearer gender differences have been 
found in affect with women reporting higher levels of PA and NA than men (Nolen-Hoeksema \& Rusting, 1999; Wood et al., 1989).

Nolen-Hoeksema and Rusting (1999) reviewed a number of possible explanations for the gender differences in moods and behaviors, including: 1) biological explanations; 2) personality explanations; and 3) social context explanations. The biological explanations for gender differences in negative mood and behaviors have focused on two sources: hormones and sex-linked genetic predispositions. However, little evidence has been found to support the explanations. For instance, research has shown that women who report having experienced significantly more negative affect during periods of hormonal change also tend to have a history of frequent depressive episodes not connected to periods of hormonal change (Parry, 1994; Parlee, 1994). The genetic studies have generally focused on aggressive behavior problems, with boys and men included in the studies almost exclusively, although Nolen-Hoeksema and Rusting (1999) assume that genetics probably play a role in determining a person's vulnerability to depression and anxiety.

Personality explanations have focused on a range of traits, behavioral styles, cognitive styles, and coping styles that may lead women and men to experience and express moods and behaviors differently. This issue, albeit in a narrower sense, is reviewed in the subsequent section when discussing the importance of different personality factors for SWB.

Wood and her colleagues (Wood, Rhodes, \& Whelan, 1989; Wood \& Rhodes, 1992; Grossman \& Wood, 1993) argued that gender differences in mood and behaviors come mainly from socially-prescribed gender roles. The content of social stereotyping "obligates" women to be more expressive of emotions, especially sadness and fear, more concerned with their own and other's emotional states, and more emotionally labile than men (Grossman \& Wood, 1993; Brody \& Hall, 1993). Thus, the traditional female gender role involves greater care-giving responsibilities, which may promote more emotional responsiveness and result in more emotional experience and expressiveness in women than in men. To assess the impact of such expectations on emotional behavior, Grossman and Wood (1993) manipulated these expectations for emotional responses and found that the extent to which women believed in gender role stereotypes (e.g., sensitivity to the needs of others) was related to self-reported emotional experience and expressiveness. When no genderspecific emotion norms were mentioned in the instructions, women reported more extreme emotion ratings (both positive and negative) than men. But when expectations for emotional responses were experimentally manipulated (i.e., when respondents were instructed to enhance or to attenuate their emotional responses), no gender difference was found. In addition to that, Robinson and 
Johnson (1997) revealed that emotion stereotypes also influence the reporting of emotions.

\subsection{Personality and general SWB}

The most consistent and robust finding in research of SWB is the importance of temperament and personality for SWB. Repeatedly it has been found that personality factors, such as extraversion, neuroticism, optimism, and selfesteem, are the strongest predictors of SWB (e.g., DeNeve \& Cooper, 1998).

A theory of temperamental predisposition for SWB posits that because of inborn individual differences in the nervous system, people have a genetic predisposition to feel happy or unhappy. However, although Tellegen and his colleagues (Tellegen, Lykken, Bouchard, Wilcox, Segal, \& Rich, 1988; Lykken $\&$ Tellegen, 1996) calculated that $40-50 \%$ of the variation in current SWB could be explained by genes, other researchers (e.g., Baker, Cesa, Gatz, \& Mellins, 1992; McGue \& Christensen, 1997) reported much lower heritability estimates.

Major personality traits that have been found to be strongly associated with SWB are extraversion (Costa \& McCrae, 1980; Watson \& Clark, 1984), neuroticism (Costa \& McCrae, 1980; Watson \& Clark, 1984), optimism (Scheier \& Carver, 1993; Marshall, Wortman, Kusulas, Hervig, \& Vickers, 1992), and self-esteem (Campbell, 1981; Diener \& Diener, 1995; Diener \& Emmons, 1985).

Research has shown that personality factors are differentially related to the components of SWB. For instance, extraversion and neuroticism were found to be more critical for the affective components of SWB than for the cognitive one (e.g., McCrae, 1983; Watson \& Clark, 1984). This has been explained by proposing that extraversion leads to PA, whereas neuroticism leads to NA, and that these phenomena, respectively, tap the same underlying construct (Costa \& McCrae, 1980). According to the authors, this temperamental perspective states that extroverts are simply more cheerful and high-spirited than introverts, whereas emotionally unstable individuals are naturally more prone to negative affect. The relationships among the constructs are strong and consistent. For instance, Fujita (1991) found a latent correlation between extraversion and positive affect of .71, while neuroticism and negative affect formed a single factor. Watson and Clark (1984) and Tellegen (1985) argued that PA and NA roughly correspond to the dominant personality factors of extraversion and neuroticism, respectively, and that the latter traits should be relabeled positive affectivity and negative affectivity, respectively. According to the authors, 
extraversion represents an inherent susceptibility to positive affect, whereas neuroticism represents an inherent susceptibility to negative affect. However, newer evidence indicates that emotional stability - that is, the positive pole of neuroticism - tends to predict positive affect better than extraversion (Vittersø, 2001).

Gray $(1971,1987)$ offered a psycho-biological explanation for the role of extraversion and neuroticism with regards to distinct emotional states. He proposed that there are two neurologically based motivational systems - the behavioral activation system (BAS) and the behavioral inhibition system (BIS) - which, respectively, regulate behavior in the presence of reward or punishment signals. The BAS and BIS have been "operationalized" in trait-like terms. Extraversion or positive emotionality has been linked to BAS, whereas neuroticism or emotional instability has been linked to BIS (Tellegen, 1985).

Based on the proposition that affect and personality tap the same underlying constructs, and on the findings by Lucas et al. (1996) that the cognitive and affective components of SWB were differentially related to theoretically relevant variables, Schimmack, Diener, and Oishi (2002a) proposed and tested a mediator model, which implied that personality factors, such as extraversion and neuroticism, influenced LS indirectly via PA and NA. That is, personality traits are responsible for the stability in trait PA and NA, and because affect balance is likely to be an important source in formulating one's GLS judgment (Suh, Diener, Oishi, \& Triandis, 1998), this stable, chronically-accessible source determines the stability in GLS. The weaker relationship between personality and LS, as compared to that between personality and affect, has been suggested to depend on other factors that are not determined by personality factors but are also likely to be important in formulating life satisfaction judgments. For instance, life satisfaction domains - such as satisfaction with academic performance and satisfaction with romantic relationships - that are important for a person's GLS have been found not to be influenced by extraversion and neuroticism (Schimmack et al., 2002a).

Headey and Wearing (1989) suggested a dynamic equilibrium model to explain the importance of personality to SWB and the stability of the reports that people give of their SWB. The authors proposed that each person has a "normal" equilibrium level of SWB that is determined by personality characteristics, especially extraversion, neuroticism, and openness to experience. SWB levels might change when experiencing negative or positive life events but personality characteristics serve to return SWB to its normal equilibrium level. Some studies have supported this theory (Suh, Diener, \& Fujita, 1996; Mehnert, Krauss, Nadler, \& Boyd, 1990). In addition to this, Headey and Wearing (1989) found that extraverts experienced more favorable events than introverts did, 
while neurotics experienced more adverse events than stable individuals did. Based on this finding, the authors suggested that there is an indirect mechanism behind the relationship of personality to SWB. That is, personal characteristics may be causal antecedents to life events, which, in turn, are antecedent to SWB.

Some researchers have suggested a congruence model (i.e., a personenvironment fit) as the possible explanation for personality's influence on SWB (e.g., Diener, Larsen, \& Emmons, 1984). According to the model, people experience high SWB only when their personality fits their environment. For instance, Moskowitz and Cote (1995) suggested that people are likely to experience high PA when they behave in accordance to their traits. The researchers found that, for example, people who reported very low agreeableness experienced unpleasant affect when engaging in agreeable behaviors and pleasant affect when engaging in quarrelsome behaviors.

Among the outside domains of the Big-Five model, optimism is probably the personality factor that is mentioned most often as a strong predictor of SWB. Optimism and pessimism have been defined as a generalized tendency to expect, respectively, positive or negative outcomes in the person's life (Scheier $\&$ Carver, 1985). Scheier and Carver suggested that optimism influences SWB through current positive expectations that people have about their future. The theoretical principles that underlie the concepts of optimism and pessimism are taken from expectancy-value models of motivation, in which the initial assumption is that behavior is organized around the pursuit of goals (e.g., Carver \& Scheier, 2002b). According to them, the more important a goal is to a person, the greater the motivation is to move towards it. Having goals, regardless of the success in achieving them, was related to higher life satisfaction (Emmons, 1986). Furthermore, it has been suggested that if the personal goals reflect the major age-related developmental tasks of the particular age period, this helps the person deal successfully with the challenges of his/her developmental environment and consequently will benefit his/her overall life adaptation and well-being (Salmela-Aro \& Nurmi, 1997; Heckhausen \& Schulz, 1999). Self-regulation processes that aim to reduce conflict among one's goals, and that have been suggested to be responsible for selecting compatible goals, may also be a critical aspect in determining SWB.

Scheier and Carver claimed that optimists and pessimists have different patterns of behavior and expectations in relation to the achievement of goals. Since optimists tend to believe that their actions will lead to a positive outcome, they persist in those actions and achieve their goals more often than pessimists, who tend to believe that they will fail and more often withdraw their efforts and disengage from the goals they have set. Scheier and Carver (1993; see also Scheier, Weintraub, \& Carver, 1986) also suggested that optimists report higher 
SWB because they manage critical life situations better than pessimists do. That is, optimists tend to deal with the source of the stress using a problem-focused coping strategy, whereas pessimists tend to avoid directly confronting the problem itself and use an emotion-focused coping strategy.

Partly against this background, Chang (2002) has suggested that affectivity serves as a mediator between particular cognitive processes, including optimism and life satisfaction. Based on the available evidence, he and his colleague suggested a model in which optimism/pessimism do not influence life satisfaction directly but are totally mediated by positive/negative affect. However, the model received only partial support. In a study with older adults, Chang and his colleague (see Chang, 2002; Chang \& Sanna, 2001) found that optimism and pessimism influenced life satisfaction both directly and indirectly through PA. However, NA was found to be an insignificant mediator between optimism/pessimism and LS. The authors concluded that NA is likely to be a mediator between positive/negative outcome expectancies and negative psychological outcomes, whereas PA is a mediator between positive/negative outcome expectancies and positive outcomes in middle-aged adults.

Most of the results reviewed in this section have been found in gender-mixed samples. However, gender differences for some traits, as for instance, traits related to neuroticism, have been consistently reported with women reporting higher levels than men (Lynn \& Martin, 1997). Women have also been found to score higher in anxiety (Feingold, 1994) and symptoms of depression (Kling, Hyde, Showers, \& Buswell, 1999). The extent to which the findings reported above apply to middle-aged women, who are studied in the present thesis, is therefore unclear.

\subsection{Socio-demographic factors and general SWB}

If social circumstances are considered separately, the ones that are most often reported to be related to general SWB are marital status, employment status, educational level, and income (for a review, see Diener et al., 1999).

A number of studies reported that married people have higher levels of happiness than people who have never married or are divorced, separated, or widowed (for a review, see Mastekaasa, 1992, 1994). In addition, unmarried people who live with a romantic partner report higher levels of happiness than unmarried people who live alone. Schoon, Hansson, and Salmela-Aro (2005), in the study of middle-aged mixed samples from three countries (the United Kingdom, Estonia, and Finland) found that married women and married men 
reported higher life satisfaction compared to their divorced counterparts. The relationship between marriage and the components of SWB remains significant, even when variables such as age and income are controlled (Gove, Hughes, \& Style, 1983). Two broad explanations of the relationship between marriage and well-being have been suggested: social causation and social selection (e.g., Joung, Stronks, van De Mheen, van Poppel, van Der Meer, \& Machenbach, 1997; Mastekaasa, 1992). The social causation theory implies that marriage increases life satisfaction by providing benefits - such as emotional and financial support - to the individual, which they would not receive if they were single. The social selection theory implies that people who are happy and welladjusted are more likely to be selected for marriage. The two hypotheses are not mutually exclusive and may operate simultaneously. Both hypotheses have received empirical support (e.g., House, Umberson, \& Landis, 1988; Horwitz, White, \& Howell-White, 1996).

Having a child has been found to be related to general SWB less often. Nevertheless, we decided to include the variable in our studies because it is reasonable to believe that the variable may be important for middle-aged women's SWB, which was the object of our study. For them, not having a child by middle-age may mean that they will never have one and this might influence their SWB to a larger extent than is the case for women of other age groups and for men. Diener (1984), reviewing the earlier research on SWB, concluded that the presence of children in the family has a negative effect or no affect on SWB. However, the results are not consistent and the analyses were mostly carried out using mixed age and gender samples (for a review, see Shields \& Wooden, 2003). Having children and bringing them up is connected with many burdens and daily worries that can influence SWB negatively. On the other hand, children play an important role in family life and childless couples tend to divorce more often than those that have at least one child.

Knowing that work is an important integral and defining aspect in adult life, it is not surprising that unemployment has been found to be an important obstacle for high SWB. Campbell et al. (1976) reported that unemployed people were among those with the lowest happiness, even when income differences were controlled (see also Björklund \& Eriksson, 1988).

Usually, only small positive correlations have been found between income and SWB, but income remains an interesting factor in research of SWB. In a number of studies, it has been found that rich people are, on average, slightly happier than poor people; however, a much stronger relationship between income and SWB is found at a national level. That is, wealthy countries seem to score much higher on happiness than poor countries (e.g., Diener et al., 1999). Similar results have been reported for education. Education and income have 
been found to correlate more with well-being in poor countries (Campbell, 1981; Diener, Sandvik, Seidlitz, \& Diener, 1993). Moreover, Clark and Oswald (1996) found that when income levels were controlled, highly-educated people were less satisfied with their lives than less highly-educated people suggesting that income expectations are important for SWB.

Broadly speaking, the relationships between socio-demographic variables and the components of SWB are usually surprisingly weak. In a widely cited book by Campbell et al. (1976), the authors reported that ten resources - including income, number of friends, religious faith, intelligence, and education - together accounted for only $15 \%$ of the variance in happiness. Different explanations have been suggested to explain these weak relationships. One important set of explanations centers around discrepancy theories. Michalos (1985) suggested the multiple discrepancy theory of satisfaction, which posits that different people compare themselves to different standards, and that a person may compare him/herself with multiple standards, such as a reference group of other persons, past circumstances, and so on. Satisfaction judgments are based on the discrepancies between the current life situation and conditions, and these standards. If a person chooses an upward comparison, such discrepancy tends to result in decreased satisfaction, whereas a downward comparison tends to result in increased satisfaction. Wood (1996) advanced a theory concerning social comparison and suggested that social comparison is "the process of thinking about information about one or more other people in relation to the self" ( $p$. 520). According to her, the processes involved in social comparison are: 1) to acquire social information (from, for example, proximate individuals); 2) to think about social information (a person observes similarities and differences between the other and the self); and 3) to react to social comparison (which can include cognitive, affective, and behavioral responses). The social comparisons have also been found to interact with the individual's personality (McFarland \& Miller, 1994).

The other group of possible explanations of the weak relationship between socio-demographic variables and SWB centers around the "hedonic trademill" theory (Brickman \& Campbell, 1971). The authors argued that after a positive/negative change, the individual quickly adapts to the new situation and returns to his/her baseline of happiness. It was found that even dramatic events, such as a spinal cord injury, seemed to have only a short-lived effect on people's SWB (Silver, 1982). However, the "hedonic trademill" theory has been contradicted by evidence indicating that people do not adapt so rapidly (and completely) to all circumstances. For instance, Stroebe and his colleagues (Stroebe, Stroebe, Abakoimkin, \& Schut, 1996) found that people who lost their partner reported a higher level of depression even after two years, compared to those who did not lose their partner. Headey and Wearing (1992) have extended 
the "hedonic trademill" theory from an adaptation theory standpoint, including the proposition that each person returns to a baseline determined by his/her own personality. That is, although SWB levels might change when experiencing negative or positive life events, personality characteristics serve to return SWB to its normal equilibrium level.

\subsection{Bottom-up/top-down approaches of SWB}

There are two theoretical perspectives regarding the way in which SWB is generated: bottom-up and top-down. The bottom-up approach asserts that SWB is determined by the balance of pleasant and unpleasant experiences in different areas. That is, a person reports high general SWB if he/she is satisfied with a majority of important domains (e.g., family life, job, and so on). By contrast, the top-down approach maintains that SWB levels are largely derived from stable personality features (Diener, 1984). That is, a "constitutionally" happy person has a general propensity to experience things in a positive way, even when circumstances are bad (Costa, McCrae, \& Norris, 1981).

A number of researchers have tested different models of causal influences on and by SWB (e.g., Feist, Bodner, Jacobs, Miles, and Tan, 1995). Generally, the results suggested a bi-directional model of causality. That is, SWB can either cause or be caused by a number of related factors. Brief et al. (1993) and Schimmack et al. (2002a) integrated both bottom-up and top-down approaches. Brief et al. (1993) concluded that both objective life circumstances (as posited by those advocating a bottom-up approach) and personality (as posited by those advocating a top-down approach) affect SWB indirectly through the interpretation of objective life circumstances. They found that objective health did not exert direct influence on the components of SWB but, in the form of subjective health that was also influenced by negative affectivity, it had significant effect on all SWB components, with the largest influence on life satisfaction and a weaker influence on affect. Schimmack et al. (2002a) interpreted variables important to SWB as possible sources that people use when making life satisfaction judgments. They proposed that people tend to rely on the same sources in forming life satisfaction judgments and that personality is responsible for the stability of these sources. 


\subsection{The person-oriented approach}

The person-oriented approach is an outgrowth of the holistic interactionistic research paradigm. The basic assumption of the paradigm is that the entire developmental system (from biology to environment) is interactive and the individual is an active participant in all these processes (Magnusson, 1988). All processes within the system are synchronized within and between the levels and any particular aspect of the system achieves its meaning through the role it plays in the total system (Cairns, McGuire, \& Gariépy, 1993; Magnusson, 1985, 1998). Bergman and Magnusson (1997) have claimed that most studied system and observed states can vary in an infinitive number of ways at a detailed level but on a global level there will often exist only a small number of more frequently observed patterns that are rather stable and that reflect "optimal" states of the system under study.

Applying the interactionistic perspective to SWB, we suggest that an important aspect of general SWB is that the components of SWB are organized in different ways within different individuals. That is, we believe that the components are the interacting keynotes of the SWB system and are formed during development in such a way that a number of typical profiles of SWB emerge that reflect the SWB structure in a more profound way. For these reasons - in addition to the standard variable-oriented analyses used in the majority of studies - in this thesis, person-oriented analyses have also been carried out. However, as argued by Bergman (1988), it is not to be expected that everyone in a sample of persons would belong to one of the emerging typical patterns.

\section{Aims of the study}

The general purpose of this thesis is to contribute to our knowledge about the relative importance of childhood factors, social circumstances, and personality in middle-aged women's SWB. The interest is focused on:

1) The importance of social circumstances for women's general SWB after controlling for personality factors (Study I). Although many researchers point to personality as the major predictor of SWB, personality factors alone only explain approximately half of the variability in SWB and the question as to what factors account for the rest of the variance remains open. 
Therefore, socio-demographic variables (which, in some cases, are more open to interventions at a societal level than personality factors) may be important as explanatory variables.

2) Cross-national differences in women's general and job-related SWB and the relative importance of different socio-demographic factors for general and job-related SWB within different countries (Study II). Cross-national differences in SWB are usually studied at the aggregated level, reporting happiness and life satisfaction to be lower in Eastern Europe compared to Western Europe, while comparisons between countries on an individual level are rare. In the present study, in addition to a cross-national comparison of general and job-related SWB in the samples of Swedish and Lithuanian employed middle-aged women, we also compared how selected sociodemographic variables influence general and job-related SWB at the individual level in these two countries.

3) The importance of optimism for women's general SWB (Study III). With the exception of the main personality factors, optimism is the factor that is mentioned most often as a strong predictor of general SWB (e.g., Lucas et al., 1996). However, the mechanism underlying the relationship between the phenomena is not known. Chang (2002) suggested a model in which affectivity mediates the relationship between optimism and global life satisfaction. Based on this model, we investigated the longitudinal relationship between early optimism, optimism in adulthood and its "effect" on GLS, both directly and indirectly via affectivity. To broaden the interpretational context, we also included selected factors measuring early adaptation.

4) Finding typical patterns of general SWB and examining their structural and individual stability across six years in middle-aged women (Study IV). In Study II, Study III, and partially in Study I, we treated the components of SWB separately, studying their relationships to a number of personality and socio-demographic factors. However, a person-oriented theoretical perspective suggests that the SWB components are likely to interact and operate together in a nonlinear fashion and that this process might lead to the crystallization of a small number of typical SWB configurations at the individual level. Therefore, using person-oriented methodology, typical patterns of general SWB and their stability over time were studied. 


\section{Methods}

\subsection{Sample}

Different samples were used in the different studies and are described there. They were all taken from those women who belonged to the main cohort of the longitudinal research program Individual Development and Adaptation (IDA; Bergman, 2000; Magnusson, 1998). IDA is a complete school grade cohort of Örebro children (all children who attended grade 3 in 1965) and children moving into Örebro after grade 3 were then added to the cohort. IDA was initiated by David Magnusson in the beginning of the 1960s and he led it until 1996, when Lars Bergman became the principal investigator.

The core of the IDA data used in this thesis comes from the data collection undertaken in 1998, when the women were 43 years old. At that time, 569 IDA women took part in a personal interview. In the context of the personal interview, five hand-out questionnaires and nine leave-after questionnaires were administered. The studied sample comprised 89.0 percent of the eligible women in the IDA cohort and can be described as being reasonably representative of Swedish women of that age living in urban communities (Bergman, 2000).

Data was also taken from an intensive psychological-medical examination directed at those women in the cohort who either lived in the Örebro region or lived elsewhere but belonged to the biomedical sub-sample. In the context of the intensive psychological-medical examination, five questionnaires were filled out by the medical staff and eight questionnaires were filled out by the women themselves. This sample comprised 369 women (77 percent of the eligible women in the cohort).

Data were also used from age $13(\mathrm{~N}=248$ women who had longitudinal data and comprised about $51 \%$ of all women who belonged to the cohort at that age) and from age $49(\mathrm{~N}=272$ women who had longitudinal data and comprised about $54 \%$ of all women who belonged to the cohort at that age). To obtain some information about how representative the two longitudinal samples were, means in selected variables were compared between the longitudinal sample and all women in the cohort for which information was available at age 13 and 49, respectively. At age 13, timidity, school satisfaction, and optimism were used as comparative variables; and at age 49, GLS, PA, and NA were used as comparative variables. No significant mean differences were found between any of the two longitudinal samples studied in the thesis and the relevant IDA cohort. It seems defensible to assume that, for the purposes of the thesis, the 
studied samples are reasonably representative of the relevant IDA cohort since the drop out at age 13 and at age 49 was low ( $6 \%$ and $18 \%$, respectively).

\subsection{Measures}

An overview of the variables used in the present thesis is presented in Table 2. Some extended information concerning the GLS scale and the Optimism scale used in the present thesis is provided below. For a more detailed description of the variables, the reader is referred to these studies.

\subsubsection{Global Life Satisfaction}

In three of the four studies included in the present thesis, the following four items were used to measure women's GLS at age 43 and 49: How satisfied are you with your life? Think about your situation during the last half year. Have the positive or the negative things outweighed? How meaningful is your life? How do you like your present life? The four-item scale showed an acceptable internal reliability at two time points (.78 and .91, at age 43 and 49 , respectively). In addition to that, in a recent data collection conducted at age 49, GLS was measured by both the four-item scale and the SWLS (Diener et al., 1985). A preliminary data analysis showed a correlation of .81 between the four-item GLS scale and the SWLS, indicating an acceptable convergent validity of the GLS scale used in the present thesis. In study II, a three-item scale of SWB was used for both the Swedish and Lithuanian samples. In the Lithuanian sample the women's GLS was assessed using three items that are identical to the first three items listed above, and therefore we decided to use the three-item scale for the Swedish sample to avoid comparability problems.

\subsubsection{Optimism}

Optimism at age 13 was measured by the Attitude to the Future scale using the semantic differential technique introduced by Charles Osgood and his colleagues (Osgood, Tannenbaum, \& Suci, 1957). Girls rated their attitude to the future on a seven-point scale of the following six relevant adjective pairs that are polar opposites: good-bad, dull-interesting, unpleasant-pleasant, kindunkind, unfair-fair, and happy-sad. Although the measure of optimism at age 13 is different from the modern optimism scales, it does tap the essence of optimism in that it is future-oriented, in semblance to Scheier and Carver's (1985) theory and a modern definition of optimism. The attitudes to the future scale also showed high internal consistency reliability $(\alpha=.89)$. 
The optimism scale by Olàh (2002) was used to assess optimism at age 43. The scale includes the following five items: I am convinced that most of the things that happen around me are positive in the long run; Even when I find myself in a difficult situation, I am convinced everything will turn out well in the end; Thoughts about my future give me good feelings; I am a person who has a very positive view towards life; People describe me as a very optimistic person. Although the scale is not very popular internationally, the items were very similar to those included in the optimism sub-scale of the Life Orientation TestRevised (LOT-R; Scheier, Carver, \& Bridges, 1994). In addition to that, in a recent IDA data collection conducted at age 49, optimism was measured both by Olàh's scale and the LOT-R. A preliminary data analysis showed a correlation of .73/-.42 between Olàh's optimism scale and the optimism/pessimism subscales of the LOT-R, respectively. This indicates an acceptable convergent validity of Olàh's optimism scale, as used in the present thesis.

\subsection{Statistical methods}

Both variable-oriented and person-oriented methods were applied in this thesis. The two more advanced methods used are briefly described below.

\subsubsection{Structural equation modeling of longitudinal relationships}

Structural equation modeling (SEM) was used in Study III to investigate the longitudinal relationships between optimism in adolescence and SWB in adulthood, and the role of affectivity in the relationship between optimism and life satisfaction in adulthood. The analyses were conducted using the maximum likelihood procedures of Lisrel 8 (Jöreskog \& Sörbom, 1996) and the analyses were based on the variance/covariance matrix computed for those subjects having complete data $(n=248)$.

SEM analyses were performed in three steps. First, indicators were constructed collapsing the items measuring Attitude to Future13, Optimism43, Positive Affect43, and Negative Affect 43 into three indicators per construct, following a procedure suggested by Brooke, Russell, and Price (1988). Then the measurement models based on the parceled scales (except Global Life Satisfaction43, which consisted of only four items that were used as indicators) were tested to see if the chosen indicators for the latent variables appropriately measured them. Finally, the fit of three structural models to data was assessed with various indices. 
Table 2. An overview of the variables

\begin{tabular}{|c|c|c|c|c|}
\hline Variable & $\mathrm{N}$ & M & SD & $\begin{array}{l}\text { Cronbach's } \\
\text { Alpha or } \\
\text { min-max }\end{array}$ \\
\hline \multicolumn{5}{|l|}{ General SWB variables at age $43 / 49$} \\
\hline Global Life Satisfaction (4 items) ${ }^{\#}$ : & $321 / 500$ & $5.59 / 4.94$ & $0.95 / 1.15$ & $.78 / .91$ \\
\hline Positive Affect (10 items) & $350 / 503$ & $3.67 / 3.71$ & $0.45 / 0.57$ & $.84 / .87$ \\
\hline Negative Affect (10 items) & $346 / 502$ & $1.75 / 1.74$ & $0.60 / 0.62$ & $.87 / .88$ \\
\hline \multicolumn{5}{|l|}{ Domain-specific SWB variables at age 43} \\
\hline Intrinsic job satisfaction (12 items) & 488 & 3.89 & 0.58 & .85 \\
\hline Extrinsic job satisfaction ( 6 items) & 477 & 3.15 & 0.84 & .83 \\
\hline Relations to partner (9 items) & 428 & 3.94 & 0.62 & .86 \\
\hline Subjective health (1 item) & 566 & 4.12 & 0.90 & \\
\hline \multicolumn{5}{|l|}{ Personality variables at age 43} \\
\hline \multicolumn{5}{|l|}{ KSP scales: } \\
\hline Negative emotionality (9 subscales) & 349 & 1.99 & 0.33 & .94 \\
\hline Aggressive non-conformity (4 subscales) & 356 & 2.24 & 0.32 & .80 \\
\hline Extraversion (3 subscales) & 353 & 2.57 & 0.29 & .81 \\
\hline Optimism (5 items) & 349 & 3.04 & 0.44 & .75 \\
\hline \multicolumn{5}{|l|}{ Socio-demographic variables at age 43} \\
\hline Personal income/month before tax deduction & 452 & 15133 & 4119 & $3000-45000$ \\
\hline Household income /month after tax deduction & 415 & 22058 & 8344 & $6300-93500$ \\
\hline Educational level (4=university degree) & 569 & \multicolumn{2}{|c|}{$33.4 \%$ university degree } & $1-4$ \\
\hline Marital status $(2=$ married/cohabiting $)$ & 567 & \multicolumn{2}{|c|}{$81.7 \%$ married/cohabiting } & $1-2$ \\
\hline Child status $(4=$ no children at all $)$ & 567 & \multicolumn{2}{|c|}{$13.9 \%$ no children at all } & $1-4$ \\
\hline Unemployment status ( $2=$ unemployed $)$ & 536 & \multicolumn{2}{|c|}{$9.1 \%$ unemployed } & $1-2$ \\
\hline Disability pension $(2=$ drew pension $)$ & 534 & \multicolumn{2}{|c|}{$4.5 \%$ drew pension } & $1-2$ \\
\hline Current studies $(2=$ studying $)$ & 567 & \multicolumn{2}{|c|}{$7.1 \%$ studying } & $1-2$ \\
\hline $\begin{array}{l}\text { Off work because of illness }(2=\text { off work at least } \\
\text { one day during the last three months })\end{array}$ & 297 & \multicolumn{2}{|c|}{$25.9 \%$ off work } & $1-2$ \\
\hline \multicolumn{5}{|l|}{ Variables at age 13} \\
\hline Attitudes to future (6 items) & 488 & 5.52 & 1.24 & .89 \\
\hline \multicolumn{5}{|l|}{ School satisfaction (4 subscales) } \\
\hline Global school-satisfaction (6 items) & 491 & 3.45 & 0.66 & .81 \\
\hline Work load (6 items) & 488 & 3.65 & 0.60 & .79 \\
\hline Relations to classmates (6 items) & 491 & 4.16 & 0.58 & .77 \\
\hline Anxiety about school work (3 items) & 491 & 3.45 & 0.81 & .60 \\
\hline Intelligence & 514 & 149.47 & 26.76 & $.95^{*}$ \\
\hline \multicolumn{5}{|l|}{ Behavior ratings (6 items) } \\
\hline Aggressiveness (7=high) & 514 & 3.56 & 1.51 & $1-7$ \\
\hline Motor restlessness ( $7=$ high $)$ & 515 & 3.51 & 1.57 & $1-7$ \\
\hline Timidity $(7=$ high $)$ & 515 & 3.93 & 1.49 & $1-7$ \\
\hline Disharmony $(7=$ high $)$ & 513 & 3.67 & 1.46 & $1-7$ \\
\hline Lack of concentration $(7=$ high $))$ & 515 & 3.58 & 1.53 & $1-7$ \\
\hline Low school-motivation (7=high) & 514 & 3.53 & 1.39 & $1-7$ \\
\hline Upbringing conditions ( $4=$ unstable upbringing) & 602 & \multicolumn{2}{|c|}{$7.3 \%$ unstable upbringing } & $1-4$ \\
\hline Parents' educational level ( $1=$ university degree) & 500 & \multicolumn{2}{|c|}{$7.2 \%$ university degree } & $1-7$ \\
\hline Family income/year $(7=50000$ SEK or more $)$ & 475 & \multicolumn{2}{|c|}{$16.0 \% 50000$ SEK or more } & $1-7$ \\
\hline
\end{tabular}

Note. ${ }^{\#}$ Two items in the Global Life Satisfaction scale that was administered to women at age 43 had eight response options, whereas at age 49 those items had seven response options. When the means of a reduced GLS scale comprised of the two items with the same response options at both age points were compared, no significant differences were found across six years. *'Split-half reliability (Härnqvist, 1962). 
The fit indices used in Study III are as follows: the chi-square statistic was used to test the differences between the estimated covariance matrix and the observed covariance matrix; because of the chi-square test's sensitivity to sample size, other fit indices were used that do not explicitly depend on sample size - the root mean square error of approximation (RMSEA; Browne \& Cudeck, 1993) and the adjusted goodness-of-fit index (AGFI; Jöreskog \& Sörbom, 1996). RMSEA is an indicator of close fit of the model to the population covariance matrix. Browne and Cudeck (1993) suggested that RMSEA values of .08 or less indicate an acceptable fit, with values of .05 or less indicating a close fit. The AGFI ranges from zero to one, where values above .90 indicate a good fit of the model to data (Bentler \& Bonett, 1980). Differences in fit between two models were also evaluated using the Akaike measure (AIC; Akaike, 1987), for which lower values represent better fit, and by using the chi-square difference test.

\subsubsection{Classification of patterns across age}

Classification of the observed individual general SWB patterns into types of patterns, where all subjects belonging to a type have a similar typical pattern, was carried out using cluster analysis within the framework of the LICUR procedure (Bergman, Magnusson, \& El-Khouri, 2003). First, a residue of multivariate outliers was removed, then the remaining subjects were cluster analyzed using Ward's (1963) agglomerative hierarchical method.

Three criteria guided in finding an appropriate number of clusters to extract:

1) theoretical meaningfulness of the cluster solution;

2) if a pronounced drop in the explained error sum of squares (EESS) occurs when a cluster solution with one less cluster is extracted; and

3 ) the size of EESS for the chosen cluster solution (it should, preferably, reach $67 \%)$.

The usefulness of a cluster solution was evaluated with regard to:

1) EESS as explained above;

2) whether the found cluster solution was significantly better than what could be expected from analyzing a "similar" random set of data (somewhat analogous to the significance test of a correlation coefficient);

3) whether the homogeneity coefficients for the clusters were acceptably low (preferably this coefficient should be less than one for standardized data);

4) the verification of that the clusters discriminate in important validation variables; and 
5) whether the correlations between the SWB variables were strongly reduced or disappeared when correlation analysis was carried out within each cluster.

In the final step of LICUR, cluster membership at the two ages (age 43 and age 49) was linked by cross-tabulation and it was looked for significantly overfrequented cells, indicating developmental types, using an exact hypergeometric test.

\subsection{Significance testing}

In the studies reported in this thesis, and additionally in the thesis summary, the results of a large number of significance tests are reported. These results must be interpreted with caution for two main reasons. Firstly, a basic assumption in many types of significance tests is that the studied samples are randomly drawn from a population. In line with most research in psychology, this was not the case here but the tradition of significance testing was followed anyway. There are some defenses for this, with one being that the testing protects against overinterpreting findings caused by errors of measurement. Secondly, when a large number of significance tests are carried out, the mass significance problem must be observed. Rather than introducing mechanical corrections for it, it was instead decided to pay attention to the strength of a significance and mainly interpret findings that were significant at a conservative level.

\subsection{Extended analyses}

Some data analyses reported in this thesis summary (I call them extended analyses) were not included in the four studies but were performed later. To shed additional light on some points a few such results are presented in the General Discussion. 


\section{Summary of the studies}

4.1.Study I. The importance of social circumstances for Swedish women's subjective well-being

\section{Background and aim}

It is well-known that social circumstances are related to adaptation and adjustment in various areas, including SWB. However, as far as we know, there has been no comprehensive study that not only presents results on the relationships between middle-aged women's social circumstances and SWB, differentiated into the three main components of general SWB (that is, global life satisfaction, positive affect and negative affect), but also takes personality factors into account. The role the personality plays in this context is only partially known. Research has constantly showed that neuroticism and extraversion are among the strongest predictors of SWB. However, the extent to which personality factors explain the relationships between social circumstances and SWB is not well known. For instance, are the relationships partly or fully caused by personality factors influencing both social circumstances and SWB? Thus, the importance of social circumstances and the role of personality factors for women's general SWB at age 43 are of interest in the study.

\section{Results}

The results showed non-existent to moderate relationships between a number of social circumstances variables and general SWB. The strongest relationship was found between marital status and GLS. Being off work because of illness and household income were the strongest predictors of NA, but the relationship was not strong. A moderate relationship was found between a cumulated social disadvantage index and SWB, indicating that extreme differences in this index were related to fairly large differences in SWB. In person-oriented analyses, when the three components of SWB are treated as "whole," social circumstances were compared between women with a typical profile of generalized low SWB and women with a typical profile of generalized aboveaverage SWB. The results indicated stronger relationships between SWB and the cumulative disadvantage index and unemployment than was the case in the variable-oriented analyses. When negative emotionality was controlled for it wiped out nearly all relationships between the social circumstances variables and SWB, except for those between GLS and marital status and unemployment. 


\section{Conclusion}

Although only moderate relationships were found between a number of selected socio-demographic variables and general SWB, the relationships are not unimportant. Both variable-oriented analyses and complementary personoriented analyses showed that some social circumstances (marital status and unemployment) were constantly related to GLS and that those relationships remained significant even when a personality variable was included in the analyses, suggesting that with regards to GLS, the importance of marital status and, to a lesser extent, unemployment is not explained by the personality factors we studied.

4.2. Study II. Swedish and Lithuanian employed women's subjective wellbeing

\section{Background and aim}

There is considerable evidence to suggest that a number of socio-demographic variables, such as marital status, having a child, education, and income to some extent predict general SWB (e.g., Diener et al., 1999). However, cross-national research on SWB needs to take into account not just the general impact of these variables, but also how these variables differently influence SWB at the individual level between countries that represent different socio-economic conditions, despite being similar in other aspects. Only a limited amount of such research has been conducted; instead the focus has been on cross-cultural comparisons in individualistic versus collectivistic countries, analyzing mean levels of SWB and how socio-economic and demographic factors are related to SWB at the national level. Therefore, the comparison of relationships at the individual level between general and job-related SWB, and socio-demographic factors in Sweden and Lithuania, presents a scientific interest. The major purposes of the study were: 1) to estimate the level and variation of general and job-related SWB in Swedish and Lithuanian employed women; and 2) to shed light on national differences in the relative importance of different sociodemographic factors for employed women's general and job-related SWB within each country.

\section{Results}

The results showed that the Swedish women scored significantly higher on each SWB component, except extrinsic job-satisfaction, than their counterparts in 
Lithuania. For the Swedish sample, the largest mean differences between different socio-demographic groups were found for GLS between married/cohabiting and single women, and between women who had at least one child and those without children. Contrary to the results found for the Swedish sample, no significant differences were found among these categories for the Lithuanian women. For the Lithuanian sample, the largest differences in all SWB components were found between women characterized by high or low education or income.

\section{Conclusion}

Our findings indicate that there are substantial differences in SWB among different socio-demographic categories within and between the two countries. The results suggest that socio-demographic factors can play a very different role in different countries, depending on such factors as living conditions, income distribution within societies, social security, and so on. The results also suggest that material wealth beyond a certain level may lose its importance, with nonmaterial family factors taking the main role.

4.3. Study III. Childhood roots of women's subjective well-being: The role of optimism

\section{Background and aim}

Optimism has consistently been found to be one of the strongest predictors of general SWB (e.g., Scheier and Carver, 1985; Carver \& Scheier, 2002a). However, almost all information about the relationship between optimism and general SWB comes from cross-sectional studies carried out in adulthood. In addition to that, what mechanism underlies the strong relationship is not fully understood. In the present study, we used structural equation modeling to test three extended cognitive-affective models, based on Chang's work (Chang, 2002). We modeled longitudinal relationships between optimism at age 13, optimism at age 43, its mediation via PA and NA measured at age 43, and finally the "effect" on GLS at age 43. The importance of a number of childhood adaptation factors for general SWB was also studied to place the results in an interpretational context.

\section{Results}

The data supported the full extended cognitive-affective model in which early optimism influenced optimism in middle-age, which in its turn affects GLS, 
both directly and indirectly via NA. Our results partially support the results by Chang and Sanna (2001). According to our model, only about a third of the influence of optimism on GLS was indirect, via affectivity, and two-thirds was direct. The model also showed a significant relationship between optimism measures across a 30-year period. Among selected childhood factors, only early optimism was found to have constant relationships to all three SWB components at age 43 .

\section{Conclusion}

The results supported the contention by Lucas et al. (1996) that life satisfaction and optimism might partly reflect the same underlying predisposition, despite the fact that the measures focus on different time frames (past and future, respectively). In addition to that, consistent to Carver and Scheier's (2002a) notion that optimists/pessimists tend to develop more positive/negative feelings, we found strong direct relationships between optimism and PA/NA, but it is likely that this affective information is only used to a lesser extent by optimists/pessimists in forming GLS judgments, whereas a kind of pre-stored evaluation or "chronic" expectancies that have been developed based on previous behavior and on earlier life situations are used to a greater extent. The longitudinal relationship between early optimism and optimism in adulthood, although of moderate strength, is noteworthy since relationships usually diminish or disappear when the intervening time period is several decades.

4.4. Study IV. Stability of typical patterns of subjective well-being in middleaged Swedish women

\section{Background and aim}

A number of studies have reported on the relationships among the three components of general SWB, as well as their relationships to personality factors and socio-demographic factors (see Diener et al., 1999, for a review). As such, the perspective has almost always been variable-oriented, studying correlations and differences between groups. However, a person-oriented approach that instead focuses on typical patterns of SWB and their stability over time is also possible. One motivation behind this alternative approach is that the SWB components are believed to interact and operate together in a nonlinear fashion and it should be of interest to study them together as an indivisible whole. The aim of this study is to establish trustworthy typical patterns of general SWB in middle-aged Swedish women and to examine their structural and individual stability across six years. 


\section{Results}

Cluster analysis resulted in a six-cluster solution at age 43. Among these clusters, a generalized positive typical pattern and two generalized negative typical patterns were found, one characterized by very high NA and one characterized by very low GLS. A cluster characterized by above-average PA and NA was also found, as well as one characterized by low PA. A strong relationship was found between membership in the clusters and the values in certain SWB-related variables, supporting the validity of the typical patterns found. In regression analyses, cluster membership contributed to the prediction of many validation variables above the prediction achieved by the three SWB components entered as continuous variables. A very similar six-cluster solution was found at age 49, indicating structural stability across six years. Five of the six clusters also showed significant individual stability across six years.

\section{Conclusion}

Six typical patterns of general SWB were identified that showed to be trustworthy in different ways. The clusters showed large differences from the reference cluster in the expected direction in a number of validation variables. Clusters were replicated six years later, indicating structural stability of the typical SWB profiles found. The reported typical patterns were also found to contain information not accounted for by using an ordinary linear variableoriented approach.

\section{General discussion}

The general purpose of this thesis is to contribute to our knowledge about the importance of childhood factors, socio-demographic factors, and personality for middle-aged women's subjective well-being (SWB). In this thesis, crosssectional as well as longitudinal findings using both variable-oriented and person-oriented methods are reported. In addition to this, cross-cultural differences in the relationship between socio-demographic factors and SWB were investigated, studying a sample of Lithuanian middle-aged employed women and comparing results to those found for the Swedish middle-aged employed women. 


\subsection{Socio-demographic factors, personality, and SWB}

The strong relationship between personality factors and SWB, and especially findings published by researchers of behavior genetics indicating a high heritability of SWB, have led some to proclaim that "trying to be happier is as futile as trying to be taller" (Lykken \& Tellegen, 1996, p. 189). However, it is probably worth proceeding with "trying to be taller" because, only about half of the variance in SWB can be explained by genetic factors or traits, and therefore, other factors that are probably more open to intervention are also of importance.

The importance of socio-demographic variables for general SWB was investigated in Study I and Study II. Consistent with the results from other studies (see Diener et al., 1999 for a review), we also found that the relationships between a number of socio-demographic variables and the components of SWB are low, explaining only $4-8 \%$ of the variance in two components of general SWB, GLS, and NA, whereas no significant sociodemographic predictors emerged for PA. Similar results were found when a cumulative disadvantage index, including seven disadvantages (e.g., being unemployed or having no children), was related to SWB. However, when we compared the scores of women without any cumulative disadvantage at all with the scores of women with the maximum obtained disadvantage, the results indicated a substantial group difference in these two SWB variables (a difference of almost one standard deviation).

When person-oriented analyses were applied, they showed stronger and clearer connections between SWB and social circumstances. The women who belonged to the extreme clusters differed substantially in the value of the cumulative disadvantage index. That is, those women who belonged to the generalized positive cluster had much fewer disadvantages than those who belonged to the generalized negative cluster. When the differences between the two clusters were studied for each specific socio-demographic variable separately, they were not usually large - except for unemployment status (4\% and $26 \%$, respectively). The findings suggest that cumulative disadvantage may be of considerable importance for the general SWB and that some separate disadvantages included in the cumulated disadvantage index (e.g., unemployment, in our case) can carry a larger risk than others. Unemployment not only brings material difficulties to one's life but also limits participation in a supportive social environment, restricts possibilities for self-actualization, and so on.

Extended analyses (not reported in the studies) showed that it may be too crude to simply sum disadvantages/advantages and relate them to general SWB. For instance, single women who belonged to the lowest income group and had at least one child reported very low GLS compared to the other women in the 
Swedish sample $(\mathrm{M}=5.24, \mathrm{SD}=1.33$, and $\mathrm{M}=6.08, \mathrm{SD}=1.04, t(279)=-$ $2.10, \mathrm{p}<.05$ ) with an effect size of 0.79 , indicating a large difference. However, no significant differences were found for affect between these groups of women. Thus, having a child or being married (see the discussion below) cannot automatically be regarded as "advantages" that enhance a person's general SWB without taking into consideration the women's situation in other respects. In addition to that, the importance of certain socio-demographic variables may also be age related. For instance, not being married or not having a child would probably not be disadvantages for a young woman who has family life ahead of her. However, as the results suggest, for a middle-aged woman for whom the established pattern of family life may last for the rest of her life, those factors are likely to be of greater importance.

When the personality variable that was most strongly related to SWB (negative emotionality) was included in the analyses, the relationships between social circumstances and SWB were almost wiped out. However, this was more pronounced for the affect components than for GLS. GLS "gained," in addition to marital status, another socio-demographic variable (unemployment) as a significant predictor, when negative emotionality was included in the regression equation; whereas NA "lost" its significant predictors among social circumstances, and PA was only ever predicted by negative emotionality. Thus, it is likely that for GLS, the importance of marital status and, to a lesser extent, unemployment is not explained by personality factors.

Although social selection theory (reviewed in the Introduction) posits that happy and well-adjusted people are more likely to be selected for marriage, our findings do not confirm that. In accordance with the findings reported by Marks (1996), our results (see also Study IV) suggest that even middle-aged women with "problematic" personalities have been selected for marriage or co-habiting. More discussion on the importance of personality characteristics for the relationships between SWB and other factors is provided below.

\subsection{SWB in a cross-cultural perspective}

To explore the generalization of the findings of Study I, we compared the importance of socio-demographic factors in two countries, Sweden and Lithuania. Results concerning the between-nation differences in SWB indicate that the Swedish middle-aged employed women were more satisfied with their lives and had a lower variability in PA compared to the Lithuanian women, who live in a less economically developed country. Several studies have found that the level of self-reported happiness in Central-Eastern Europe is much below 
that of Western Europe (Inglehart \& Klingemann, 2000; see also Schoon et al., 2005). One possible explanation is that people from individualistic and collectivistic (I-C) countries rely on different sorts of information to make life satisfaction judgments. On a scale ranging from 1 (most collectivistic) to 10 (most individualistic), Lithuania is rated as a collectivistic country with an I-C rating of 4.00, whereas Sweden is rated as an individualistic country with an I-C rating of 7.55 (Suh et al., 1998). It has been found that in individualistic countries, personal attitudes are more influential for GLS, while in collectivistic countries the normative components (i.e., normative desirability of life satisfaction) are more important (Enker, 1987). In addition to that, Suh et al. found that emotional experiences are more important in formulating one's life satisfaction judgments in individualistic countries compared to collectivistic ones.

Delhey (2004) studied differences in life satisfaction among 10 countries that entered the EU in 2004 (Lithuania was among these countries) and compared them to the 15 countries that constituted the EU before this enlargement (Sweden was among these countries). He named cultural norms as one factor that, together with a number of other possible factors including personality, cultural norms of showing satisfaction, political culture, and so on, were likely to be important for a person's reported SWB. However, he concluded that most probably "livability" (that is, individual opportunity for need fulfillment) plays the main role among the factors that influence life satisfaction in the 10 less affluent countries. That is, people's varying life satisfaction levels are likely to reflect different "livabilities" within society. According to Delhey, no affluent country had a population with dramatically low life satisfaction and no poor country had a very satisfied population. Furthermore, Ryan and Deci (2001) argued that national poverty "can block access to exercising competencies, pursuing interests, and maintaining relationships, which would provide psychological need satisfaction" (p.153) and therefore influence an individual's GLS.

The results concerning the differential importance of socio-demographic factors in the two countries were interesting. The analyses within each country showed that in the Swedish sample, the largest differences in GLS were found for family-oriented variables; that is, between married/co-habiting and single women, and between women who had at least one child and those without children. For the Lithuanian sample, these differences were not significant. Instead, for the Lithuanian sample, the main differences in all SWB components were found between categories with different educational levels and different personal income, whereas for the Swedish sample these differences were insignificant. 
One explanation for this nation difference in the results is that people living in more affluent countries are less subject to economic pressures and therefore they give more weight to family life and good relationships with neighbors and other people (Delhey, 2004). In Sweden, income is relatively evenly distributed and few Swedes live in poverty. Thus, it is not surprising that income is more important for the Lithuanian women's SWB. Under the transition period, after Lithuania became independent, the gaps between the income groups in Lithuania have become larger. Even employed people belonging to the lower income groups can barely meet their basic needs and that certainly affects their SWB. Although the theory of "hedonic trademill" posits that people tend to adapt to many changed conditions/situations, it is reasonable to believe that fulfillment of basic needs remains a threshold for a person's normal functioning and well-being, including SWB. In addition to that, it has been suggested that income is more related to SWB in less developed countries because people there tend to choose as reference point material needs that are based on a worldwide standard and that often are far above their actual income (Ahuvia \& Friedman, 1998). Cultural aspects are also likely to play an important role. For instance, the Japanese report considerably less happiness than the country's economic prosperity would predict (Diener, Diener, \& Diener, 1995).

Education covaries with income and perhaps due to this, education is related to general SWB (Campbell, 1981). It is likely that well-educated people are able to find more rewarding and better paid jobs, and therefore to fulfill their material needs. However, education may have other indirect effects on general SWB as well. For instance, gaining a better education may contribute to an increase in SWB by allowing a person to attain or make progress towards their goals. On the other hand, education may raise expectations. If those expectations cannot be met, that may lower the SWB (Diener et al., 1999). For instance, Clark and Oswald (1994) found that highly-educated people reported being more distressed than less-educated people when they were unemployed. Unrealized expectations about job rewards - which are negatively related to satisfaction also tend to increase with education (e.g., Bowles \& Gintis, 1976; Arvey, Carter, \& Buerkley, 1991).

The results of Study II suggest that material wealth beyond a certain level loses its importance, after which non-material family factors take the main place. However, income may have a larger importance for some social groups of Swedish women. As mentioned in the previous section, single women who had at least one child and belonged to the lowest income group reported very low GLS.

If income is such a critical factor for a person's life satisfaction when the economic conditions of a country are bad, economical growth and change in 
wealth in Lithuania should be accompanied by rising SWB and by a shift in the relative importance of the predictors of SWB. However, this prognosis may be doubtful since longitudinal findings suggest that growing national income does not pay off in much-increased life satisfaction. Although some countries - for instance, Greece and Portugal - reported higher life satisfaction in the beginning of their economic growth (in the middle of the 1990s), no linear trend in growing life satisfaction has been found in these countries (Delhey, 2004). However, it is suggested that probably, if progress occurs rapidly and is stronger than expected, growing aspirations would not countervail the increase in SWB and therefore economic success may indeed result in enhancement of GLS, especially if the former economic level was low (Hagerty \& Veenhoven, 2003; Delhey, 2004). A replication study on a new Lithuanian sample in 5-10 years would provide additional data relevant to this issue.

\subsection{The importance of childhood factors for SWB in middle age}

In Study III, we investigated how strongly adaptation in adolescence is related to SWB in adulthood. The results showed that optimism, as measured by attitude to the future at age 13, was consistently, but not strongly, related to women's SWB at age 43, and furthermore, that this relationship was stronger than the (almost non-existent) relationships between the other factors (for example, behavior ratings, school satisfaction, conditions of upbringing, and so on) studied in early adolescence and adult SWB.

On the one side, the results are heart-warming, indicating that even such factors as having an unstable upbringing with many family changes or behavior problems do not have an appreciable influence on SWB in adulthood. On the other side, it might be argued that the absence of strong longitudinal relationships was only to be expected, since among those other factors, no personality factor was included. However, we studied a number of variables that have been shown to have rather strong longitudinal relationships to adult adjustment in areas other than SWB, such as aggression and coming from a broken home with regard to later social adjustment and criminality (Wångby, Bergman, \& Magnusson, 1999; Klinteberg, Andersson, Magnusson, \& Stattin, 1993). To some degree, the "negative" result that was found might be a genderspecific phenomenon, since it has been noted by Robins (1986) that early behavior in girls may be less predictive of later outcomes than early behavior in boys.

An important issue when discussing longitudinal relationships is fading relationships over very long time periods (e.g., Mednick, Harway, \& Finello, 
1984). This general tendency is likely to emerge because of the influence of cumulative and unpredictable events. For instance, in a study by Zettergren, Bergman, and Wångby (in press), also using the IDA database, the relationship between peer rejection in childhood and adjustment at age 43 was studied in a number of areas and only a few significant relationships were found; while other longitudinal studies within this area, covering a shorter time-span, have found significant and strong relationships. Against this background, the relationship we found between optimism in adolescence and SWB at age 43 is notable.

In Study III, we also tested a model based on Chang's (2002) model. Chang originally proposed that affectivity serves as a complete mediator between particular cognitive phenomena, including life satisfaction and optimism. However, when the proposition was tested empirically by Chang and his colleague, the results showed that optimism and pessimism influence LS directly and indirectly via PA, whereas NA failed to serve as a mediator between the phenomena (Chang \& Sanna, 2001). We also found that optimism affected GLS both directly and indirectly. In our case, NA served as a significant mediator between the phenomena. However, in our study, the direct relationships between PA and GLS, and NA and GLS were rather similar (.15 and .22, respectively) - although significant only for NA - and extended analyses showed that those relationships did not differ significantly. Chang and Sanna found a direct relationship of .21 between PA and LS. Thus, these findings are inconsistent to a lesser extent. In addition to this, the structural relationships we found in adulthood are stronger than the standardized regression coefficients they found. This can be explained by the fact that we used SEM that allowed us to estimate correlations or path coefficients among the variables without measurement error and those relationships tend to be of a larger magnitude than the relationships between similar observed variables found in regression analyses.

Generally speaking, our results suggest that only a third of the influence optimism had on GLS was indirect via affectivity, and two-thirds was direct. More than one explanation is possible for this finding. That the studied phenomena to some extent tap the same underlying construct might be one possible reason for strong direct relationships. That is, although life satisfaction and optimism focus on different time frames (past and future, respectively), the concepts may reflect the same underlying predisposition (Lucas et al., 1996). The other possible explanation for the strong direct relationship might be due to the sources people rely on to form their life satisfaction judgments. Based on global, positive expectations for the future, optimists might have a kind of prestored evaluation of their life on which they might rely when judging their global life satisfaction. That is, people not only constantly develop expectancies 
but sometimes they retrieve "chronic" expectancies from memory that have been developed based on previous behavior and earlier life situations (see also Schimmack et al., 2002a).

The strong direct relationships between adult optimism and PA or NA found in Study III are consistent with the proposition made by Carver and Scheier (1990; $2002 \mathrm{~b}$ ). They suggested that high expectations for future outcomes go together with positive feelings and that doubtful expectations for future outcomes go together with negative feelings. Thus, although optimists/pessimists tend to develop more positive/negative feelings, our results suggest that this affective information is only used for evaluating global life satisfaction to a lesser extent, while, as mentioned above, "chronic" expectancies retrieved from memory are likely to be of larger importance when forming global life satisfaction judgments.

Summing up, optimism is an important feature for high general SWB. Although optimists tend to experience more positive emotions and less negative emotions, those are only to a lesser extent responsible for the strong relationship between optimism and GLS. Our results are consistent with the proposition that a person who has a generalized expectancy of good outcomes in life tended also to have "chronic" positive expectancies that are to a large extent used when evaluating life as a whole. It would be of interest to explore whether the same holds for people in different cultural groups. In Study II, we found that there were substantial differences in general SWB in two neighboring countries that differ largely in their social circumstances. Thus, if life satisfaction and optimism largely reflect the same underlying predisposition, and if optimism is an important "spring" for developing a high level of positive affect and a low level of negative affect, it would be of interest to see how strongly these phenomena are related in countries such as Lithuania, as compared to other more affluent countries - in this case, Sweden.

\subsection{The importance of studying patterns of SWB}

Although research on SWB has been very fertile over the past few decades, almost only variable-oriented approach has been applied, while a personoriented approach is not only possible but is needed to obtain a complete picture of how the main components of SWB interact and operate together at the individual level. For the studied sample of Swedish middle-aged women, a trustworthy typology of typical patterns of general SWB has been demonstrated, indicating the existence of one generalized positive and two negative typical patterns of general SWB - a typical pattern that seems to reflect an intensity of 
affect, an average general SWB typical pattern, and a typical pattern characterized by low PA (Study IV). Five out of six typical patterns (=clusters) showed individual stability across six years.

As mentioned in the previous section, when investigating the importance of socio-demographic variables for general SWB, we in some ways obtained stronger and clearer relationships when two extreme clusters (i.e., the typical high/low SWB patterns) were compared on a number of socio-demographic variables than we obtained in variable-oriented analyses. In addition to this, an interesting finding regarding the role of marital status emerged when variableoriented analyses were complemented with person-oriented ones. Although in Study I we found that marital status together with unemployment status remained significant predictors of Swedish women's GLS, when negative emotionality was included in the regression analyses in Study IV, the results showed that women who were married but dissatisfied with the relationship to their partner belonged to a generalized negative SWB profile, reporting very low GLS. In contrast, women from the generalized positive cluster reported high satisfaction with their relationship to their partner. These findings suggest that marriage, as an objective fact, probably doesn't have a strong or continuous effect on a person's SWB, however, marital satisfaction does (see also Dush \& Amato, 2005).

The women from Cluster 1 ( $36 \%$ of the sample), that is, those belonging to the cluster with generalized positive SWB, reported being optimistic and extraverted, having very good relationships with their partners, and were healthy and satisfied with their job. In contrast, women from Cluster 3 (7\% of the sample), that is, those belonging to the cluster with generalized negative SWB, especially high in NA, scored low on optimism and high on neuroticism, reported low intrinsic job satisfaction, and low subjective health. These typical extreme patterns showed both structural and individual stability. In extended analyses, the relationship between childhood factors and these two extreme clusters were studied. However, 30 years ago, the girls from both these clusters reported being equally satisfied with school, had equally good relationships with their classmates, and so on. Paralleling the results reported in Study III, the clearest difference already 30 years ago was that those girls who belonged to the generalized positive cluster had a more positive attitude to their future than those who, at age 43, belonged to the generalized negative SWB cluster $(\mathrm{d}=$ 0.54). An interesting detail is that none of the girls that, at age 13, had an unstable upbringing with many family changes belonged to the generalized negative cluster; they were all living with their father and mother during their entire childhood. However, we did not include measures of the parents' relationships to each other and to the girl, and, in general, we didn't study the home atmosphere in those "stable" families. Thus, maybe "stable family" per se 
does not guarantee the quality of upbringing in the family.

Most often, extraversion is indicated as a trait that is "essential" for high SWB. However, Emmons and Diener (1986) found that the two components of extraversion - sociability and impulsivity - influence different components of SWB. That is, the sociability component of extraversion was found to be responsible for the relation between extraversion and positive affect, whereas the impulsivity items were not correlated with positive affect and therefore act to reduce the correlation between the overall extraversion scale and positive affect. Extended variable-oriented analyses partially confirmed the finding by Emmons and Diener, and indicated that sociability was significantly correlated to all three SWB components; whereas impulsivity was weakly related only to GLS and PA. Extraversion in our studies was defined to include impulsiveness, monotony avoidance, and detachment (that is, the opposite pole of sociability), and extended analyses were performed to explore whether women who belonged to different clusters differ significantly on the three traits. Results showed that although the women belonging to the extreme clusters differ significantly in extraversion, the main difference lay in their level of sociability $(\mathrm{d}=0.82)$, while they differed neither in impulsivity nor in monotony avoidance. Thus, the finding suggests that women characterized by generalized positive SWB are likely to have more close social relationships, whereas women characterized by generalized negative SWB are more distant and withdrawn, and are not likely to be involved in close personal relationships with others.

Cluster 2 ( $7 \%$ of the sample) comprised women above average in both PA and NA. The cluster was unexpected from a variable-oriented perspective, since the correlation between PA and NA for the total sample was negative. Although the women from the generalized positive cluster (Cluster 1) and those from the intense-affect cluster (Cluster 2) scored much higher on extraversion, extended analyses showed that the women scored differently on the sub-scales included in the extraversion scale. That is, no significant differences were found for impulsivity or sociability, but the women from those clusters differed substantially on monotony avoidance $(\mathrm{d}=0.58)$. That is, the women with the intense-affect profile (Cluster 2), were likely to have higher need for change and action, thrill seeking, and avoiding routine.

It probably needs to be explained why we suppose that Cluster 2 primarily reflects intense-affect, and not only frequent-PA/NA. Although PANAS (Watson et al., 1988) is primarily a measure of how frequently a person feels PA and NA, the terms included in the PA and NA sub-scales are also high in activation (see the Introduction). Diener and Emmons (1985) suggested that PA and NA at trait level vary inversely in frequency, but they covary together on an 
intensity dimension (Diener et al., 1985). They found that when intensity is "partialed" out, the negative correlation between PA and NA increased substantially. Although the PA and NA sub-scales of PANAS are primarily interpreted in terms of valence (that is, positively-valenced and negativelyvalenced terms) and are intended to measure frequency of PA and NA, the subscales are also likely, to some extent, to measure intensity of PA/NA.

An interesting finding is that, usually, the negative-normal cluster differences were larger than the positive-normal difference, raising the question of possible non-linear relationships between the general SWB structure and certain SWBrelated variables, so that the relationship may in some cases be stronger in the low value range of these variables than in their high range. (However, it must be pointed out that this line of reasoning is weakened by the fact that the generalized positive SWB cluster is larger than the generalized negative cluster and thus can be regarded as less extreme). To focus on one direction of the causality: it is an intriguing thought that the importance of many SWB-related variables for general SWB could more be the importance of negative adaptation in these variables for a low SWB than the importance of positive adaptation for a high SWB. This line of reasoning is in accordance with the one reported by Robinson-Whelen et al. (1997). Studying optimism versus pessimism in older adults, they concluded that it is more important for well-being not to be pessimistic than it is to be optimistic.

Summing up, the findings reported here indicate an alternative way of representing the relationship structure among the three general SWB components in terms of typical patterns, instead of in terms of correlations. The typical SWB profiles that were reported merit replication studies to see if they generalize. If this is the case, the types we found can be regarded as a compact way of representing the relationship structure of general SWB; a representation that also takes interactions and non-linear relationships among the SWB components into account.

\subsection{The components of general SWB}

As mentioned in the Introduction, it is widely accepted that SWB can be regarded as consisting of two major facets: a cognitive judgment of life satisfaction (Andrews \& Withey, 1976) and an emotional aspect that includes positive affect and negative affect (Diener \& Emmons, 1985). SWB might be considered as an overall latent construct (e.g., Liang, 1984), however, most often, the cognitive and affective components are studied separately and considered as lower-order facets of SWB (e.g., Diener, 1994; Vittersø \& Nilsen, 
2002). Other conceptualizations of the components are also possible and have been suggested by, for instance, Suh et al. (1998) and Schimmack, Radhakrishnan, Oishi, Dzokoto, and Ahadi (2002b; see also Schimmack et al., 2002a). They suggested that LS can be regarded as being the effect of PA and NA. In the present thesis, the components of SWB were studied in both ways. It is likely that the traditional lower-order structure of SWB, which was mainly relied on in this thesis, sets limits to the SWB mechanisms that can be studied.

The affective facet of SWB has received a lot attention with regards to both its conceptualization and measurement. These issues are reviewed in more detail in the Introduction section. In this thesis, PA and NA were measured by PANAS (Watson et al., 1988), a questionnaire that is widely used to measure affect. Although it has been shown that PANAS is a reliable and valid questionnaire and that the PA and NA sub-scales are internally consistent and stable (Watson et al., 1988), the instrument has also been criticized (e.g., by Larsen \& Diener, 1992). The main critique of PANAS is that its sub-scales do not cover the full range of the positive and negative affect domain. That is, terms that are generally accepted as defining positive affect - for instance happy, satisfied; or negative affect - for instance, unhappy, sad, depressed, are missing in the PANAS instrument. For that reason, nowadays the frequency of specific positive/negative emotions (e.g., joy and sadness) or specific terms concerning pleasant/unpleasant affect (e.g., cheerful and downhearted) are usually used to measure the affective components of general SWB. Those measures of affect have been suggested to be more closely related to the concept of SWB (Larsen \& Diener, 1992).

SWB can, to some extent, be considered both as a trait and a state. In this thesis, we are primarily interested in trait SWB and our analyses showed that the stability coefficients across six years are moderately high, with the highest relationship found for NA (.67). Although there is evidence that momentary mood influences people's responses to SWB questions, despite the time frame specified in the instruction (Schwarz \& Strack, 1999), the measures we obtained are likely to be trait-like. Personality factors have been found to play a major role in creating stability of the components of general SWB. This issue is reviewed in the Introduction and is also discussed in subsequent sections.

Furthermore, some researchers have argued that traditional measures of SWB do not cover all important aspects of a person's well-being. For instance, Caprara and his colleagues have suggested that the cognitive component of general SWB should be extended by adding optimism and self-esteem, and those variables - together with life satisfaction - would comprise a latent dimension that the authors refer to as "positive thinking" (Caprara \& Steca, 2004; Caprara, \& Steca, 2005). However, although it is likely that these 
phenomena to some extent share a common latent dimension, other studies have shown that the general SWB components also have unique parts (Lucas et al., 1996).

Vittersø (2003) argued that the definition of SWB is missing a challenge dimension that would add - in addition to current measures that tap what is pleasant and typical about life -what is interesting and challenging. Somewhat related to this, Allardt (1976) introduced the concept of "having, loving, and being." He stressed that the dimension "being," which includes needs for personal growth, was of great importance for a person's well-being. The dimension is included in PWB and the relationship between the approaches is discussed in section 5.7.

\subsection{The direction of relationships - bottom-up/top-down approaches}

The approaches of bottom-up and top-down to explain causal directions in SWB mechanisms are defined in more detail in the Introduction. Even if the issue of the direction of relationships is not a central one in the present thesis, it was indirectly touched upon in some of the studies in this thesis.

A number of studies have tested both bottom-up and top-down models in which the direction of relationships to and from SWB are considered. However, the word "causal" seldom emerges in trying to explain the relationships. In the literature (e.g., Bollen, 1989), three conditions are generally pointed out as needing to be satisfied in order to make causal inferences about relationships in non-experimental settings. First, there has to be time precedence of the cause over the effect (that is, $\mathrm{X}$ must precede $\mathrm{Y}$ in time). Second, a covariation of the expected sign between the two variables is necessary. Third, spurious variables that may account for the association between the two variables must be eliminated. While a longitudinal design could satisfy the first and second conditions, the third condition can only be partially satisfied in nonexperimental research.

Feist et al. (1995) compared how well two models of SWB (bottom-up and topdown) fit the data and found that both models showed good fit. That is, according to their models, SWB could be regarded as directly influenced by physical health, daily hassles, world assumptions, and constructive thinking, as well as SWB being regarded as having a direct influence on all these variables. Brief et al. (1993) and Schimmack et al. (2002a) went a step further and tested models in which they integrated both bottom-up and top-down approaches. Brief et al. concluded that both objective life circumstances (as posited by those 
advocating the bottom-up approach) and personality (as posited by those advocating the top-down approach) affect SWB indirectly through the interpretation of objective life circumstances.

Schimmack et al. (2002a; 2002b) interpreted variables important to SWB as possible sources that people use when making life satisfaction judgments. They proposed that people over time tend to rely on the same sources in forming life satisfaction judgments and that personality is responsible for the stability of these sources. Furthermore, Schimmack et al. found that hedonic balance was found to mediate the influence of personality traits on life satisfaction, whereas life satisfaction domains - such as satisfaction with academic performance and satisfaction with romantic relationships - were not influenced by extraversion and neuroticism. That affectivity is likely to mediate relationships between personality factors and GLS was also suggested by extended analyses of our data. Results showed that the relationships of GLS to negative emotionality and extraversion ( $r=-.49$ and $r=.20$, respectively) were almost wiped out when PA and NA were controlled for. Only the relationship between GLS and negative emotionality remained significant, but it was strongly diminished $(r=-.18$.)

For some purposes, the direction of the causal relationships just discussed is of obvious importance. For instance, should we recommend that for Swedish society, the primary road to further improve the subjective well-being of its citizens is through influencing psychological factors at the individual level and, to some extent, through supporting stable marital/co-habitation relationships and reducing unemployment? Or should we just join those claiming that "trying to be happier is as futile as trying to be taller" (Lykken \& Tellegen, 1996, p. 189)? The findings of this thesis to some extent support the first view. Although cross-cultural research has shown that the improvement of SWB is not an easy task, it is worth trying because SWB is one indicator of the quality of life of a society, and a well-functioning and happy society is what every country is striving for.

\subsection{The relationship between PWB and SWB}

Although, as mentioned in the Introduction, PWB and SWB have evolved from two separate traditions, increasing evidence draws connections between the two. Ryff and Keys (1995) found moderate associations between SWB and two PWB scales (self-acceptance and environmental mastery), whereas the remaining four dimensions of PWB (autonomy, personal growth, positive relations with others, and purpose in life) showed mixed or weak relationships to the components of SWB. King and Napa (1998) found that respondents 
perceived both happiness and meaning as determinants of the desirability of good life. Extended analyses of the sample at age 49 show that relationships among the three components of general SWB, on the one hand, and the six dimensions of PWB, on the other hand, ranged from small (lowest $r=.18, \mathrm{p}<$ .001 , between GLS and Autonomy) to moderately strong $(r=.65, \mathrm{p}<.001$, between GLS, and Self-Acceptance). These results suggest that a person who reports a high level of SWB to some extent tends to report a high level of PWB, especially with regard to self-acceptance. Keyes, Shmotkin, and Ryff (2002), notice that although SWB and PWB are highly-correlated latent constructs (the latent correlation was found to be .70), each is a distinct facet of overall wellbeing. The aspects that most strongly separate the two conceptions are the existential aspects of PWB (that is, purpose in life and personal growth), but, as pointed out before, such aspects have also been suggested for inclusion in SWB by some researchers working within the SWB tradition. Although high SWB is probably not always a sufficient condition for high PWB or mental health (Diener, Suh, \& Oishi, 1997), these two aspects together are likely to be complementary in describing good/bad psychological functioning.

\subsection{A sociological perspective}

Although SWB is now often considered as a research subject in psychology, the phenomenon primarily emerged in sociology, as a result of a search for useful indicators of quality of life. For instance, the aim of Bradburn's work (1969) that provided the initial distinction between PA and NA was to learn how changes in society (e.g., changes in employment patterns or changes in education levels) influenced changes in people's life situation and, in turn, their psychological well-being. Andrews and Withey (1976) and Campbell et al. (1976) added that a relevant aspect of people's life quality is how people perceive the objective environment they live in.

The insight that macro-level indicators of economic performance were imprecise and crude in the 1960s led to the initiation of the Scandinavian tradition of welfare research that was primarily concerned with the living conditions of individual citizens and their families. Sten Johansson and his colleagues were the initiators of the tradition that has remained since then as a key approach to the analysis of welfare problems (Fritzell \& Lundberg, 2005).

In addition to that, as pointed out above, in 1972 the sociologist Allardt (1976) introduced the concept of "having, loving, and being" when designing an early Scandinavian welfare survey. However, at that time mostly objective indicators were measured - including living and environmental conditions, number of 
relationships to other people, and people's relation to society and nature. Twenty years later, he argued that the Swedish "level of living" approach was too narrow and extended it by adding to the already existing objective dimensions a subjective dimension, which included measures of subjective feelings of satisfaction/dissatisfaction with living conditions, subjective feelings about social relations, and subjective feelings of personal growth/alienation (Allardt, 1993). Of course, the sociological perspective has only been hinted at here. It includes many different approaches and a considerable body of research, as mentioned in the Introduction. However, this lies outside the frame of the present thesis.

The current thesis supported that the objective "having" dimension is of some importance, however the importance of the objective factors for a person's SWB is likely to go through the "lenses" of a person's subjective evaluations (e.g., Brief et al., 1993). More research on the connection between the objective and subjective "worlds" of SWB-related factors would be of interest for future research.

\subsection{Limitations and future directions}

\subsubsection{Self-reports}

The SWB data analyzed in this thesis were from self-reports. The main shortcomings of such data concern conscious distortion, social comparison, situational and contextual factors, and so on (e.g., Schwarz \& Strack, 1999; Diener et al., 1999). It is often claimed that people consciously report being happier than they really are. Several factors - such as ego-defense and social desirability - may be responsible for this distortion. Social comparison also plays an important role. Different people measure their behaviors and emotions by different standards, and that may lower the validity of ratings and blur the results of statistical analyses focusing on inter-individual differences. However, it is possible that relationships between SWB-related factors and SWB are less distorted by such biases than mean levels of SWB are. Furthermore, it has been suggested that people may have no idea about their life satisfaction and the answer to the question(s) is developed at the time the question is asked (Schwarz \& Strack, 1999). Although they argued that life satisfaction judgments are highly sensitive and dependent upon situational and contextual influences, Schimmack and Oishi (2005) and other psychologists (see also Diener \& Lucas, 1999; Diener \& Suh, 1999) have come to a different conclusion. Schimmack and Oishi examined what type of information, temporarily or chronically accessible (that is, situational or dependent on personality factors), is used for 
making life satisfaction judgments. The authors found that both types of information influence life satisfaction judgments, but that the latter is more important.

Methods other than traditional self-reports have also been used to measure SWB. For example, a person's SWB has been estimated using informant (peer, spouse) reports. Often, only a moderate convergence of self-reports and informant reports has been found. Pavot, Diener, Colvin, and Sandvik (1991) reported that in two studies the correlation between peer estimated and selfreported LS were of .54 and .64. Similar correlations were obtained when peerestimated and self-reported affect balance was correlated (.51 and .57). Other possible methods, such as coding of vocal tone and facial expressions during an interview, social behaviors, appearance, body language, and the like, can, to some degree, reflect a person's level of happiness and SWB. However, such ratings, although of obvious interest, are likely only to be weakly related to actual SWB (Veenhoven, 1991) and it seems that the person's own evaluation of his or her well-being is likely to remain a primary source of information about the person's well-being.

\subsubsection{Limitation to females}

The present thesis only concerns women. This may be treated both as a limitation and as a strength of the thesis. It is rare to study solely female samples within the SWB area; usually the studies are not gender specific. Although few studies have found mean gender differences in GLS or in a general SWB index (e.g., Haller \& Hadler, 2006), some gender differences have been reported both in negative affect (for a review, see Nolen-Hoeksema \& Rusting, 1999) and in positive affect (e.g., Wood, Rhodes, \& Whelen, 1989), and in the variability of GLS and PA. These findings suggest that some gender differences exist and that more research of gender differences in the SWB area is called for. For instance, gender differences in the relationships of other factors to SWB have not been studied very much and would be an interesting area for future study.

\subsubsection{The need for more cross-cultural research}

The sample studied in this thesis appears to be reasonably representative of Swedish urban populations of middle-aged women (Bergman, 2000) but, of course, the results reported here might to some degree be Sweden-specific. The variable-oriented results reported in the thesis are rather consistent with those 
found in other affluent EU countries, and the national comparison study (Study II) showed to some degree similar patterns of differences between Sweden and Lithuania, paralleling differences found between affluent and less affluent countries reported in other studies (Delhey, 2004; Suh et al., 1998). If the proposition held by sociologists is true - that wealth is a critical factor for determining people's life satisfaction - more research at the individual level within countries with different levels of affluence would probably contribute to our understanding of the importance of wealth for SWB (Johnson \& Krueger, 2006). Although it has been argued that material wealth beyond a certain level loses its importance, how low or high this threshold is remains to be investigated. In addition to this, in a changing society such as Lithuania, do cultural norms for life satisfaction change and lose their importance for general SWB? Replication studies in affluent countries with a larger variation in social circumstances would also be helpful here.

\subsubsection{The need for more longitudinal research}

Longitudinal research would be of great help not only for studying the direction of the causal relationships between general SWB and other factors, but also for indicating life periods and life events that play a major role in a person's SWB. Our longitudinal findings suggested that many childhood factors, such as having an unstable upbringing with many family changes or girls' behavioral problems, do not have an appreciable relationship to SWB in middle age. However, further studies concerning the identification of crucial events or time periods that may serve as turning points in a person's life would be of interest. Such factors may have a larger effect on a person's subsequent SWB than those included in this thesis. For women within the IDA program, longitudinal data concerning SWB in middle adulthood have recently become available with the addition of data from age 49. They will be used in future analyses.

\subsection{Concluding remarks}

Finally I would like to express some reflections of what I regard as important outcomes of my research and some additional suggestions for future research.

1. Enhancement of SWB at the societal level is likely to be possible via manipulation of selected socio-demographic conditions, although such conditions have consistently been shown to be less important for SWB than personality factors. Contrary to what is the case for personality factors, where single such factors have been shown to be of importance, the findings of this thesis suggest that certain combinations of socio-demographic 
conditions might be of more importance for SWB than is indicated by the, often weak, relationships between single socio-demographic factors and SWB. For instance, we showed that single women having at least one child and belonging to the lowest income group reported much lower GLS compared to other women. Further research along these lines would require more in depth information about social conditions than were available for the sample studied in the present thesis. For instance, information about social networks and about very detailed living conditions would be helpful. The sample would also have to be large, considering that certain interesting combinations of socio-demographic conditions are infrequent. It is then also important to have good measures of personality factors to be able to study their interactive effect together with the socio-demographic variables being studied and to have longitudinal data to increase the possibilities for making causal inferences.

2. It is important to further study the factors involved in making SWB evaluations and the mechanisms underlying these evaluations. The findings of the thesis suggest that marital status and to a lesser extent unemployment affect middle-aged women's GLS even when controlling for personality. And that some women tend to use a kind of a pre-stored evaluation of their life satisfaction of which they rely on when judging their global life satisfaction. Although self-report scales are the most popular method for collecting information concerning SWB, other types of measures can give beneficial information regarding factors important for evaluating SWB and its underlying mechanisms. Such information could be collected using, for instance, think-aloud protocols or experience sampling.

3. The study of SWB is rarely carried out within a person-oriented framework. This is a promising complementary approach to the standard variableoriented approach since it naturally takes nonlinearities and interactions into account. However, when carrying out person-oriented research in this area there are problems since (1) the theories in this area are usually not formulated within this framework which, in turn, creates some difficulties in formulating adequate hypotheses and (2) the empirical results in the SWB literature almost exclusively come from variable-oriented studies and can be difficult to relate to results found when using a person-oriented approach.

4. Integration of PWB and SWB into a coherent framework would allow more effective research of factors that promote a person's optimal functioning. Despite the fact that SWB and PWB originate from different traditions as well as emphasize different factors on what makes a person happy, both are associated and could be used as complementary ways of studying good/bad psychological functioning. 
5. SWB plays an important role in the field of positive psychology. The importance of the area is underlined by the 1998 American Psychological Association presidential address by Martin Seligman, in which he put forward that psychology should re-orientate itself from being a "victimology" to becoming a positive social science for the $21^{\text {st }}$ century (APA, 1998). In the SWB research we usually study factors and conditions that directly or indirectly produce happiness and unhappiness or factors that enhance or diminish global life satisfaction. Along the lines with "positive" science, we should increase research on "the positive side," even if traditional SWB research includes both positive and the negative aspects. It is however important that both aspects be studied in their own right, probably in separate studies, since different mechanisms may operate in forming high SWB and low SWB.

Much SWB research has been carried out since Wilson's review (1967) on happiness. Yet, there are many questions to be answered (some are indicated in the present thesis). Keeping in mind the plethora of unanswered questions along with changing social circumstances in the world today, it is clear that more research efforts at the methodological and theoretical level be put towards in the SWB area.

\section{References}

Ahuvia, A. C., \& Friedman, D. C. (1998). Income, consumption and subjective well being: Toward a composite macromarketing mode. Journal of Macromarketing, 18, 153-168.

Akaike, H. (1987). Factor analysis and AIC. Psychometrika, 52, 317-332.

Allardt, E. (1976). Dimensions of welfare in a comparative Scandinavian study. Acta Sociologica, 19, 227-240.

Allardt, E. (1993). Having, Loving, Being: An Alternative to the Swedish Model of Welfare Research. In M. Nussbaum \& A. K. Sen (Eds.), The Quality of Life (pp. 88-94). Oxford: Clarendon Press.

Andrews, F. M., \& Withey, S. B. (1976). Social indicators of well-being. New York: Plenum Press.

Andrews, F. M., \& Robinson, J. P. (1991). Measures of subjective well-being. In J. P. Robinson, P. R. Shaver, \& L. S. Wrightsman (Eds.), Measures of Personality and Social Psychological Attitudes (pp. 61-114). San Diego, CA: Academic Press

Argyle, M., Martin, M., \& Crossland, J. (1989). Happiness as a function of personality and social encounters. In J. P. Forgas \& J. M. Innes (Eds.), Resent advances in social psychology: An international perspective (pp. 189-203). Amsterdam: Elsevier. 
Arvey, R. D., Carter, G. W., \& Buerkley, D. K. (1991). Job satisfaction: Dispositional and situational influences. International Journal of Industrial and Organizational Psychology, 6, 359-383.

Baker, L. A., Cesa, I. L., Gatz, M., \& Mellins, C. (1992). Genetic and environmental influences on positive and negative affect: Support for a two-factor theory. Psychology and Aging, 7, 158-163.

Bentler, P. M. (1969). Semantic space is (approximately) bipolar. Journal of Psychology, 71, 33-40.

Bentler, P. M., \& Bonett, D. G. (1980). Significance test and goodness-of -fit in the analysis of covariance structures. Psychological Bulletin, 88, 588-606.

Bergman, L. R. (1988). You can't classify all of the people all of the time. Multivariate Behavioral Research, 23, 425-441.

Bergman, L. R. (2000). Women's health, work, and education in a life-span perspective. Technical report 1: Theoretical background and overview of the data collection. Report from the project Individual Development and Adaptation (IDA), No. 70. Stockholm: Department of Psychology, Stockholm University.

Bergman, L. R., \& Magnusson, D. (1997). A person-oriented approach in research on developmental psychopathology. Development and Psychopathology, 9, 291-319.

Bergman, L. R., Magnusson, D., \& El-Khouri, B. M. (2003). Studying individual development in an interindividual context: A person-oriented approach. Vol. 4 in D. Magnusson (Ed.), Paths through life. Mahwah, NJ: Erlbaum.

Björklund, A., \& Eriksson, T. (1998). Unemployment and mental health: A survey of Nordic research. Scandinavian Journal of Social Welfare, 7, 219-235.

Bollen, K. A. (1989). Structural equations with latent variables. New York: John Wiley \& Sons.

Bowles, S., \& Gintis, H. (1976). Schooling in capitalist America. New York: Basic Books.

Bradburn, N. M. (1969). The structure of psychological well-being. Chicago, IL: Aldine.

Brickman, P., \& Campbell, D. T. (1971). Hedonic relativism and planning the good society. In M. H. Appley (Ed.), Adaptation-level theory (pp. 287-305). New York: Academic Press.

Brief, A. P., Butcher, A. H., George, J. M., \& Link, K. E. (1993). Integrating bottom-up and top-down theories of subjective well-being: The case of health. Journal of Personality and Social Psychology,64, 646-653.

Brody, L. R., \& Hall, J. A. (1993). Gender and emotion. In M. Lewis \& J. M. Haviland (Eds.), Handbook of emotions (pp. 447-460). New York: Guildford Press.

Brooke, P. P., Russell, D. W., \& Price, J. L. (1988). Discriminant validation of measures of job satisfaction, job involvement, and organizational commitment. Journal of Applied Psychology, 2, 139-145.

Browne, M. W., \& Cudeck, R. (1993). Alternative ways of assessing model fit. In K. A. Bollen \& J. S. Long (Eds.), Testing structural equation models (pp. 136-162). Newbury Park, CA: Sage.

Cacioppo, J. T., \& Berntson, G. G. (1994). Relationship between attitudes and evaluative space. A critical review with emphasis on the separability of positive and negative substrates. Psychological Bulletin, 115, 401-423.

Cairns, R. B., McGuire, A. M., \& Gariépy, J.-L. (1993). Developmental behavior genetics: Fusion, correlated constraints, and timing. In A. Angold \& D. Hay (Eds.), Precursors and causes in development and psychopathology (pp. 87-122). New York: Wiley.

Campbell, A. (1981). The sense of well-being in America: Resent patterns and trends. New York: McGraw-Hill. 
Campbell, A., Converse, P. E., \& Rodgers, W. L. (1976). The quality of American life. New York: Russell Sage Foundation.

Caprara, G. V., \& Steca, P. (2004). Conceptualization and assessment of positive thinking. Paper under review.

Caprara, G. V., \& Steca, P. (2005). Affective and social self-regulatory efficacy beliefs. European Psychologist, 10, 275-286.

Carver, C. S., \& Scheier, M. F. (1990). Origins and functions of positive and negative affect: A control-process view. Psychological Review 97, 19-35.

Carver, C. S., \& Scheier, M. F. (2002a). Optimism. In C. R. Snyder \& S. J. Lopez (Eds.), Handbook of positive psychology (pp. 231-243). Oxford: University Press.

Carver, C. S., \& Scheier, M. F. (2002b). Optimism, pessimism, and self-regulation. In E. C. Chang (Ed.), Optimism \& pessimism. Implications for theory, research, and practice (pp. 31-52). Washington, DC: American Psychological Association

Chang, E. C. (2002). Cultural differences in psychological distress in Asian and Caucasian American college students: Examining the role of cognitive and affective concomitants. Journal of Counseling Psychology, 49, 47-59.

Chang, E. C., \& Sanna, L. J. (2001). Optimism, pessimism, and positive and negative affectivity in middle aged adults: A test of a cognitive-affective model of psychological adjustment. Psychology and Aging, 16, 524-531.

Clark, A. E., \& Oswald, A. J. (1996). Satisfaction and comparison income. Journal of Public Economics, 61, 359-381.

Costa, P. T., \& McCrae, R. R. (1980). Influence of extraversion and neuroticism on subjective well-being: Happy and unhappy people. Journal of Personality and Social Psychology, 38, 668-678.

Costa, P. T., McCrae, R. R., \& Norris, A. H. (1981). Personal adjustment to aging: Longitudinal prediction from neuroticism and extraversion. Journals of Gerontology, 36, 78-85.

Cowen, E. L. (1991). In pursuit of wellness. American Psychologist, 46, 404-408.

Delhey, J. (2004): Life satisfaction in the enlarged Europe. European Foundation for the Improvement of Living and Working Conditions, Office for Official Publications of the European.

DeNeve, K. M., \& Cooper, H. (1998). The happy personality: A meta-analysis of 137 personality traits and subjective well-being. Psychological Bulletin, 124, 197-229.

Diener, E. (1984). Subjective well-being. Psychological Bulletin, 95, 542-575.

Diener, E. (1994). Assessing subjective well-being: Progress and opportunities. Social Indicators Research, 103-157.

Diener, E. (2000). Subjective well-being. The science of happiness and a proposal for a national index. American Psychologist, 55, 34-43.

Diener, E., \& Diener, M. (1995). Cross-cultural correlates of life satisfaction and self-esteem. Journal of Personality and Social Psychology, 68, 653-663.

Diener, E., Diener, M., \& Diener, C. (1995). Factors predicting the subjective well-being of nations. Journal of Personality and Social Psychology, 69, 851-864.

Diener, E., \& Emmons, R. A. (1985). The independence of positive and negative affect. Journal of Personality and Social Psychology, 47, 1105-1117.

Diener, E., Emmons, R. A., Larsen, R. J., \& Griffin, S. (1985). The satisfaction with life scale. Journal of Personality Assessment, 49, 71-75.

Diener, E., \& Iran-Nejad, A. (1986). The relationship in experience between different types of affect. Journal of Personality and Social Psychology, 50, 1031-1038. 
Diener, E., Larsen, R. J., \& Emmons, R. A. (1984). Person x situation interactions: choise of situations and congruence response models. Journal of Personality and Social Psychology, 47, 580-592.

Diener, E., Larsen, R. J., Levine, S., \& Emmons, R. A. (1985). Intensity and frequency: Dimensions underlying positive and negative affect. Journal of Personality and Social Psychology, 48, 1253-1265.

Diener, E., \& Lucas, R. E. (1999). Personality and subjective well-being. In D. Kahneman, E. Diener, \& N. Schwarz (Eds.), Well-being: The foundations of hedonic psychology (pp. 213-230). New York: Russell-Sage.

Diener, E., \& Lucas, R. E. (2000). Explaining differences in societal levels of happiness: Relative standards, need fulfillment, culture, and evaluation theory. Journal of Happiness Studies, 1, 41-78.

Diener, E., Sandvik, E., Seidlitz, L., \& Diener, M. (1993). The relationship between income and subjective well-being: Relative or absolute? Social Indicators Research, 28, 195-223.

Diener, E., \& Suh, E. M. (1999). National differences in subjective well-being. In D. Kahneman, E. Diener, \& N. Schwarz (Eds.), Well-being: The foundations of hedonic psychology (pp. 434-452). New York: Russell-Sage.

Diener, E., Suh, E. M., Lucas, R. E., \& Smith, H. L. (1999). Subjective well-being: three decades of progress. Psychological Bulletin, 125, 276-302.

Diener, E., Suh, E. M., \& Oishi, S. (1997). Resent findings on subjective well-being. Indian Journal of Clinical Psychology, 24, 25-41.

Dush, C. M. K. \& Amato, P. R. (2005). Consequences of relationship status and quality for subjective well-being. Journal of Social and Personal Relationships, 22, 607-627.

Ekman, P. (1992). An argument for basic emotions. Cognition and Emotion, 6, 169-200.

Emmons, R. A. (1986). Personal strivings: An approach to personality and subjective wellbeing. Journal of Personality and Social Psychology, 51, 1058-1068.

Emmons, R. A. \& Diener, E. (1986). Influence of impulsivity and sociability on subjective well-being. Journal of Personality and Social Psychology, 50, 1211-1215.

Enker, M. S. (1987). Attitudinal and normative variables as predictors of cheating behavior. Journal of Cross-Cultural Psychology, 18, 315-330.

Erikson, R., \& Uusitalo, H. (1987). The Scandinavian approach to welfare research. In R. Erikson, E. J. Hansen, S. Ringen \& H. Uusitalo (Eds.), The Scandinavian Model: Welfare states and welfare research (pp. 177-193). Armonk, N.Y.: Sharpe.

Feingold, A. (1994). Gender differences in personality: A meta-analysis. Psychological Bulletin, 116, 429-456.

Feist, G. J., Bodner, T. E., Jacobs, J. F., Miles, M., \& Tan, V. (1995). Integrating top-down and bottom-up structural models of subjective well-being: A longitudinal investigation. Journal of Personality and Social Psychology, 68, 138-150.

Frijda, N. H. (1999). Emotions and hedonic experience. In D. Kahneman, E. Diener, \& N. Schwarz (Eds.), Well-being: The foundations of hedonic psychology (pp. 190-210). New York: Russell-Sage.

Fritzell, J., \& Lundberg, O. (2005). Fighting inequalities in health and income - One important road to welfare and social development. In O. Kangas, J. \& Palme (Eds.), Social Policy and Economic Development in the Nordic Countries (pp. 164-185). UNRISD Series. New York, Basingstoke, Palgrave.

Fujita, F. (1991). An investigation of the relation between extraversion, neuroticism, positive affect and negative affect. Master's thesis, University of Illinois.

Ganzach, Y. (2003). Intelligence, education, and facets of job satisfaction. Work and Occupations, 30, 97-122, 
Glenn, N. D. (1990). Quantitative research on marital quality in the 1990s: A critical review. Journal of Marriage and the Family, 52, 818-831.

Gove, W. R., Hughes, M., \& Style, C. B. (1983). Does marriage have positive effects on the psychological well-being of the individual? Journal of Health and Social Behavior, 24, 122-131.

Gray, J. A. (1971). The psychophysiological basis of introversion-extraversion. Behavior Research and Therapy, 8, 249-266.

Gray, J. A. (1987).Perspectives on anxiety and impulsivity: A commentary. Journal of Research in Personality, 21, 493-509.

Green, D. P., Goldman, S. L., \& Salovey, P. (1993). Measurement error masks bipolarity in affect ratings. Journal of Personality and Social Psychology, 64, 1029-1041.

Grossman, M., \& Wood, W. (1993). Sex differences in emotional intensity: A social role explanation. Journal of Personality and Social Psychology, 65, 1010-1022.

Hagerty, M. R., \& Veenhoven, R. (2003). Wealth and happiness revisited - Growing national income does go with greater happiness. Social Indicators Research, 64, 1-27.

Haller, M., \& Hadler, M. (2006). How social relations and structures can produce happiness and unhappiness: An international comparative analysis. Social Indicators Research, 75, 169-216.

Haring, M. J., Stock, W. A., \& Okun, M. A. (1984). A research synthesis of gender and social class as correlates of subjective well-being. Human Relations, 37, 645-657.

Härnqvist, K. (1969). Nya normer för DBA i årskurs 6 [New norms for DBA in grade 6]. Stockholm, Sweden: Skandinaviska Testförlaget.

Headey, B., \& Wearing, A. (1989). Personality, life events, and subjective well-being: Toward a dynamic equilibrium model. Journal of Personality and Social Psychology, 57, 731-739.

Headey, B., \& Wearing, A. (1992). Understanding happiness: A theory of subjective wellbeing. Melbourne: Longman Cheshire.

Heckhausen, J., \& Schulz, R. (1999). Biological and societal canalizations and individuals' developmental goals. In J. Brandtstädter \& R. Lerner (Eds.), Action and selfdevelopment: Theory and research through the life-span (pp. 67-103). London: Sage Publications.

Hooker, K., \& Siegler, I. C. (1992). Separating apples from oranges in health ratings: Perceived health includes psychological well-being. Behavior, Health, and Aging, 2, 8192.

Horwitz, A. V., White, H. R., \& Howell-White, S. (1996). Becoming married and mental health: A longitudinal study of a cohort of young adults. Journal of Marriage and the Family, 58, 895-907.

House, J. S., Umberson, D., \& Landis, K. (1988). Structures and processes of social support. Annual Review of Sociology, 14, 293-318.

Hunter, J. E., \& Schmidt, F. L. (1990). Methods of meta-analysis: Correcting error and bias in research findings. Newbury Park, CA: Sage.

Inglehart, R., \& Klingemann, H. D. (2000). Genes, culture, and happiness. In E. Diener \& E. Suh (Eds.), Subjective well-being across cultures (pp. 165-184). Cambridge, MA: MIT Press.

Johnson, W., \& Krueger, R. F. (2006). How money buys happiness: Genetic and environmental processes linking finances and life satisfaction. Journal of Personality and Social Psychology, 90, 680-691.

Joung, I. M. A., Stronks, K., Van De Mheen, H., Van Poppel, F. W. A, van Der Meer, J. B. W., \& Machenbach, J. P. (1997). The contribution of intermediary factors to marital 
status differences in self-reported health. Journal of Marriage and the Family, 59, 476490.

Jöreskog, K., \& Sörbom, D. (1996). Lisrel 8: User's reference guide. Chicago, IL: Scientific Software International, Inc.

Kahneman, D., Diener, E., \& Schwarz, N. (1999). Preface. In D. Kahneman, E. Diener \& N. Schwarz (Eds.), Well-being: The foundations of hedonic psychology (pp. ix-xii). New York: Russell-Sage.

Keyes, C. L. M., Shmotkin, D., \& Ryff, C. D. (2002). Optimizing well-being: The empirical encounter of two traditions. Journal of Personality and Social Psychology, 82, 10071022.

King, L. A., \& Napa, C. K. (1998). What makes a life good? Journal of Personality and Social Psychology, 75, 156-165.

Kling, K. C, Hyde, J. S., Showers, C. J., \& Buswell, B. N. (1999). Gender differences in selfesteem: A meta-analysis. Psychological Bulletin, 125, 470-500.

Klinteberg af, B., Andersson, T., Magnusson, D., \& Stattin, H. (1993). Hyperactive behavior in childhood as related to subsequent alcohol problems and violent offending: A longitudinal study of male subjects. Personality and Individual Differences, 15, 381-388.

Kubovy, M. (1999). On the pleasures of the mind. In D. Kahneman, E. Diener \& N. Schwarz (Eds.), Well-being: The foundations of hedonic psychology (pp. 134-154). New York: Russell-Sage.

Larsen, J. T., McGraw, A. P., \& Cacioppo, J. T. (2001). Can people feel happy and sad at the same time? Journal of Personality and Social Psychology, 81, 684-696.

Larsen, R. J. (1992). Neuroticism and selective encoding and recall of symptoms: Evidence from a combined concurrent-retrospective study. Journal of Personality and Social Psychology, 62, 480-488.

Larsen, R. J., \& Diener, E. (1992). problems and promises with the circumplex model of emotion. Review of Personality and Social Psychology, 13, 25-59.

Laukka, P. (2004). Vocal expression of emotion. Unpublished doctoral dissertation, Uppsala University, Sweden.

Lazarus, R. S. (1991). Progress on a cognitive-motivational-relational theory of emotion. American Psychologist, 46, 819-834.

Liang, J. (1984). Dimensions of the life satisfaction index A: A structural formulation. Journal of Gerontology, 39, 613-622.

Lucas, R. E., Diener, E., \& Suh, E. (1996). Discriminant validity of well-being measures. Journal of Personality and Social Psychology, 71, 616-628.

Lykken, D. T., \& Tellegen, A. (1996). Happiness is a stochastic phenomenon. Psychological Science, 7, 186-189.

Lynn, R., \& Martin, T. (1997). Gender differences in extraversion, neuroticism, and psychoticism in 37 countries. Journal of Social Psychology, 137, 369-373.

Magnusson, D. (1985). Implications of an interactional paradigm for research on human development. International Journal of Behavioral Development, 8, 115-137.

Magnusson, D. (1988). Individual development from an interactional perspective. A longitudinal study. Vol. 1 in D. Magnusson (Ed.), Paths through life. Hillsdale, NJ: Erlbaum.

Magnusson, D. (1998). The logic and implications of a person approach. In R. B. Cairns, L. R. Bergman, \& J. Kagan (Eds.), Methods and models for studying the individual (pp. 3363). New York, NY: Sage.

Magnusson, D., \& Bergman, L. R. (2000). Individual development and adaptation: The IDA program. In C.-G. Janson (Ed.), Seven Swedish longitudinal studies in the behavioral sciences (pp. 115-139). Stockholm: FRN. 
Marks, N. F. (1996). Flying solo at midlife: Gender, marital status, and psychological wellbeing. Journal of Marriage and the Family, 58, 917-932.

Marshall, G. N., Wortman, C. B., Kusulas, J. W., Hervig, L. K., \& Vickers, R. R. Jr. (1992). Distinguishing optimism from pessimism: Relations to fundamental dimensions of mood and personality. Journal of Personality and Social Psychology, 62, 1067-1074.

Mastekaasa, A. (1992). Marriage and psychological well-being: Some evidence on selection into marriage. Journal of Marriage and the Family, 54, 901-911.

Mastekaasa, A. (1994). Psychological well-being and marital dissolution. Journal of Family Issues, 15, 208-228.

McCrae, R. R. (1983). Extraversion is not a filter, neuroticism is not an outcome: A reply to Lawton. Experimental Aging Research, 9, 73-76.

McFarland, C., \& Miller, D. T. (1994). The framing of relative performance feedback: Seeing the glass as half empty or half full. Journal of Personality and Social Psychology, 66, 1061-1073.

McGue, M., \& Christensen, K. (1997). Genetic and environmental contributions to depression symptomatology: Evidence from Danish twins 75 years of age and older. Journal of Abnormal Psychology, 106, 439-448.

Mednick, S. A., Harway, M., \& Finello, K. M. (1984). Handbook of Longitudinal Research: Teenage and Adult Cohorts. Greenwood Pub Group.

Mehnert, T., Krauss, H. H., Nadler, R., \& Boyd, M. (1990). Correlates of life satisfaction in those with disabling conditions. Rehabilitation Psychology, 35, 3-17.

Michalos, A. C. (1985). Multiple discrepancies theory (MDT). Social Indicators Research, $16,347-413$.

Moskowitz, D. S., \& Coté, S. (1995). Do interpersonal traits predict affect? A comparison of three models. Journal of Personality and Social Psychology, 69, 915-924.

Nolen-Hoeksema, S., \& Rusting, C. (1999). Gender differences in well-being. In D. Kahneman, E. Diener \& N. Schwarz (Eds.), Well-being: The foundations of hedonic psychology (pp. 330-352). New York: Russell-Sage.

Okun, M. A., Stock, W. A., Haring, M. J., Witter, R. A. (1984). Health and subjective wellbeing: A meta-analysis. International Journal of Aging and Human Development, 19, 111-132.

Olàh, A. (2002, October). Positive traits: Flow and psychological immunity. Paper presented at the First International Positive Conference, Washington, DC.

Osgood, C. E., May, W. H., Miron, M. S. (1975). Cross-cultural universals of affective meaning. Champaign: University of Illinois Press.

Osgood, C. E., Tannenbaum, P. H., \& Suci, G. J. (1957). The measurement of meaning. Urbana: University of Illinois Press.

Parlee, M. B. (1994). Commentary on the literature review. In J. H. Gold \& S. K. Severino, (Eds.), Premenstrual dysphorias (pp. 149-167). Washington, D. C.: American Psychiatric Association Press.

Parry, B. L. (1994). Biological correlates of premenstrual complaints. In J. H. Gold \& S. K. Severino, (Eds.), Premenstrual dysphorias (pp. 47-66). Washington, D. C.: American Psychiatric Association Press.

Pavot, W., \& Diener, E. (1993). Review of the satisfaction with life scale. Psychological Assessment, 5, 164-172.

Pavot, W., Diener, E., Colvin, R., \& Sandvik, E. (1991). Further validation of the Satisfaction With Life Scale: Evidence for the cross-method convergence of self-report well-being measures. Journal of Personality Assessment, 57, 149-161. 
Robins, L. N. (1986). The consequences of conduct disorder in girls. In D. Olweus, J. Block, and M. Radke-Yarrow (Eds.), Development of antisocial and prosocial behavior (pp. 385-414). New York: Academic Press.

Robinson, M. D., \& Johnson, J. T. (1997). Is it emotion or is it stress?: Gender stereotypes and the perception of subjective experience. Sex Roles, 36, 235-258.

Robinson-Whelen, S., Kim, C., MacCallum, R., \& Kiecolt-Glaser, J. K. (1997). Distinguishing optimism from pessimism in older adults: Is it more important to be optimistic or to not be pessimistic? Journal of Personality and Social Psychology, 73, $1345-1353$.

Russell, J. A. (1979). Affective space is bipolar. Journal of Personality and Social Psychology, 37, 345-356.

Russell, J. A. (1980). A circumplex model of affect. Journal of Personality and Social Psychology, 39, 1161-1178.

Russell, J. A., \& Carroll, J. M. (1999). On the bipolarity of positive and negative affect. Psychological Bulletin, 125, 3-30.

Russell, J. A., \& Mehrabian, A. (1977). Evidence for three-factor theory of emotions. Journal of Research in Personality, 11, 273-294.

Ryan, R. M., \& Deci, E. L. (2001). To be happy or to be self-fulfilled: A review of research on hedonic and eudaimonic well-being. In S. Fiske (Ed.), Annual Review of Psychology (Vol. 52, pp. 141-166). Palo Alto, CA: Annual Reviews, Inc.

Ryff, C.D. (1995). Psychological well-being in adult life. Current Directions in Psychological Science, 4, 99-104.

Ryff, C.D., \& Keyes, C. L. M. (1995). The structure of psychological well-being revisited. Journal of Personality and Social Psychology, 69, 719-727.

Ryff, C.D., \& Singer, B. (1998). The contours of positive human health. Psychological Inquiry, 9, 1-28.

Ryff, C.D., \& Singer, B. (2000). Interpersonal flourishing: A positive health agenda for the new millennium. Personality and Social Psychology Review, 4, 30-44.

Salmela-Aro, K., Nurmi, J-E. (1997). Goal Contents, well-being, and life context during transition to university: A Longitudinal Study. International Journal of Behavioral Development, 20, 471-491.

Scheier, M. F., \& Carver, C. S. (1985). Optimism, coping, and health: Assessment and implications of generalized outcome expectancies. Health Psychology, 4, 219-247.

Scheier, M. F., \& Carver, C. S. (1993). On the power of positive thinking: The benefits of being optimistic. Current Directions in Psychological Science, 2, 26-30.

Scheier, M. F., Carver, C. S., \& Bridges, M. W. (1994). Distinguishing optimism from neuroticism (and trait anxiety, self-mastery, and self-esteem): A reevaluation of the Life Orientation Test. Journal of Personality and Social Psychology, 67, 1063-1078.

Scheier, M. F., Weintraub, \& Carver, C. S. (1986). Coping with stress: Divergent strategies of optimists and pessimists. Journal of Personality and Social Psychology, 51, $1257-$ 1264.

Schimmack, U., Diener, E., \& Oishi, S. (2002). Life-satisfaction is a momentary judgment and a stable personality characteristic: The use of chronically accessible and stable sources. Journal of Personality, 70, 345-385.

Schimmack, U., Radhakrishnan, P., Oishi, S., Dzokoto, V., \& Ahadi, S. (2002). Culture, personality, and subjective well-being: Integrating process models of life-satisfaction. Journal of Personality and Social Psychology, 82, 1313-1329.

Schimmack, U., \& Oishi, S. (2005). The influence of chronically and temporarily accessible information on life satisfaction judgements. Journal of Personality and Social Psychology, 89, 395-406. 
Schoon, I., Hansson, L., \& Salmela-Aro, K. (2005). Combining work and family life: Life satisfaction among married and divorced men and women in Estonia, Finland, and the UK. European Psychologist, 10, 309-319.

Schwarz, N., \& Strack, F. (1999). Reports of subjective well-being: Judgemental processes and their methodological implications. In D. Kahneman, E. Diener, \& N. Schwarz (Eds.), Well-being: The foundations of hedonic psychology (pp. 61-84). New York: RussellSage.

Shields, M., \& Wooden, M. (2003). Investigating the Role of Neighbourhood Characteristics in Determining Life Satisfaction. Melbourne Institute Working Paper Series wp2003n24, Melbourne Institute of Applied Economic and Social Research, The University of Melbourne.

Silver, R. L. (1982). Coping with an undesirable life event: A study of early reactions to physical disability. Unpublished doctoral dissertation, Northwestern University, Evanston, IL.

Stroebe, W., Stroebe, M., Abakoumkin, G., \& Schut, H. (1996). The role of loneliness and social support in adjustment to loss: A test of attachment versus stress theory. Journal of Personality and Social Psychology, 70, 1241-1249.

Suh, E., Diener, E., \& Fujita, F. (1996). Events and subjective well-being: Only recent events matter. Journal of Personality and Social Psychology, 70, 1091-1102.

Suh, E., Diener, E., Oishi, S., \& Triandis, H. C. (1998). The shifting basis of life satisfaction judgments across cultures: emotions versus norms. Journal of Personality and Social Psychology, 74, 482-493.

Tait, M., Padgett, M. Y., \& Baldwin, T. T. (1989). Job and life satisfaction: a reevaluation of the strength of the relationship and gender effects as a function of the date of the study. Journal of Applied Psychology, 74, 502-507.

Tellegen, A. (1985). Structures of mood and personality and their relevance to assessing anxiety, with an emphasis on self-report. In A. H. Tuma \& J. D. Maser (Eds.), Anxiety and the anxiety disorders (pp. 681-706). Hillsdale, NJ: Erlbaum.

Tellegen, A., Lykken, D. T., Bouchard, T. J., Jr., Wilcox, K. J., Segal, N. L., \& Rich, S. (1988). Personality similarity in twins reared apart and together. Journal of Personality and Social Psychology, 54, 1031-1039.

Tellegen, A., Watson, D., \& Clark, L. A. (1994, August). Modeling dimensions of mood. In L. A. Feldman (Chair), Mood: Consensus and controversy. Symposium conducted at the $102^{\text {nd }}$ Annual Convention of the American Psychological Association, Los Angeles.

Veenhoven, R. (1991), Questions on happiness: classical topics, modern answers, blind spots, in Strack, F., M. Argyle and N. Schwarz, Subjective Well-Being (pp. 7-26), Pergamon Press, Oxford.

Vittersø, J. (2001). Personality traits and subjective well-being: Emotional stability, not extraversion, is probably the important predictor. Personality and Individual Differences, 31, 903-914.

Vittersø, J. (2003). Flow Versus Life Satisfaction: How cartoons can illustrate the difference between the evaluation approach and the intrinsic motivation approach to subjective quality of life. Journal of Happiness Studies, 4, 141-167.

Vittersø, J., \& Nilsen, F. A. (2002) The conceptual and relational structure of subjective wellbeing, neuroticism, and extraversion: neuroticism is again found to be the important predictor of happiness. Social Indicators Research, 57, 89-118.

Ward, J. H. (1963). Hierarchical grouping to optimize an objective function. Journal of the American Statistical Association, 58, 236-244.

Warr, P., Barter, J., \& Brownbridge, G. (1983). On the independence of positive and negative affect. Journal of Personality and Social Psychology, 55, 128-141. 
Waterman, A. S. (1993). Two conceptions of happiness: Contrasts of personal expressiveness (eudaimonia) and hedonic enjoyment. Journal of Personality and Social Psychology, 64, 678-691.

Watson, D., \& Clark, L. A. (1984). Negative Affectivity: The disposition to experience aversive emotional states. Psychological Bulletin, 96, 465-490.

Watson, D., Clark, L. A., \& Tellegen, A. (1988). Development and validation of brief measures of positive and negative affect: The PANAS scales. Journal of Personality and Social Psychology, 54, 1063-1070.

Watson, D., \& Tellegen, A. (1985). Towards a consensual structure of mood. Psychological Bulletin, 98, 219-235.

Watson, D., \& Tellegen, A. (1999). Issues in the dimensional structure of affect-effects of descriptors, measurement error, and response formats: Comment on Russell and Carroll (1999). Psychological Bulletin, 125, 601-610.

Watson, D., Wiese, D., Vaidya, J., \& Tellegen, A. (1999). The two general activation systems of affect: Structural findings, evolutionary considerations, and psychobiological evidence. Journal of Personality and Social Psychology, 76, 820-838.

Watten, R. G., Vassend, D., Myhrer, T., \& Syversen, J. L. (1997). Personality factors and somatic symptoms. European Journal of Personality, 11, 57-68.

Wångby, M., Bergman, L. R., \& Magnusson, D. (1999). Development of adjustment problems in girls: what syndromes emerge? Child Development, 70, 678-699.

Williams, K. (2003). Has the future of marriage arrived? A contemporary examination of gender, marriage, and psychological well-being. Journal of Health and Social Behavior, 44, 470-487.

Wilson, W. (1967). Correlates of avowed happiness. Psychological Bulletin, 67, 294-306.

Wood, J. V. (1996). What is social comparison and how should we study it? Personality and Social Psychology Bulletin, 22, 520-537.

Wood, W., \& Rhodes, N. D. (1992). Sex differences in interaction style in task groups. In C. Rodgeway (Ed.), Gender, interaction, and inequality (pp. 97-121). New York: SpringerVerlag.

Wood, W., Rhodes, N. D., \& Whelan, M. (1989). Sex differences in positive well-being: A consideration of emotional style and marital status. Psychological Bulletin, 106, 249264.

Zettergren, P., Bergman, L. R., \& Wångby, M. (In press). Girls' stable peer status and their adulthood adjustment. International Journal of Behavioral Development.

Zevon, M. A., \& Tellegen, A. (1982). The structure of mood change: An ideographic/nomothetic analysis. Journal of Personality and Social Psychology, 43, 111122. 